\title{
THE EFFECT OF INFORMATION ON PRODUCT QUALITY: EVIDENCE FROM RESTAURANT HYGIENE GRADE CARDS*
}

\author{
Ginger Zhe Jin AND Phillip Leslie
}

This study examines the effect of an increase in product quality information to consumers on firms' choices of product quality. In 1998, Los Angeles County introduced hygiene quality grade cards to be displayed in restaurant windows. We show that the grade cards cause (i) restaurant health inspection scores to increase, (ii) consumer demand to become sensitive to changes in restaurants' hygiene quality, and (iii) the number of foodborne illness hospitalizations to decrease. We also provide evidence that this improvement in health outcomes is not fully explained by consumers substituting from poor hygiene restaurants to good hygiene restaurants. These results imply the grade cards cause restaurants to make hygiene quality improvements.

\footnotetext{
*A prior version of this paper circulated under the title "The Effects of Disclosure Regulation: Evidence from Restaurants". We thank Paul Devereux, Shirit Einav, Ronald Goettler, Joseph Hotz, Thomas Hubbard, Guido Imbens, Daniel Kessler, Rachel Kranton, Seth Sanders and Joel Waldfogel for valuable input. We're particularly grateful to Daniel Ackerberg for his advice. We also thank the Los Angeles County Department of Health Services and the California State Board of Equalization for allowing us to access the data. Financial support for this research was generously provided through NSF grants SES-0112295 (Jin) and SES-0112344 (Leslie). Correspondence can be addressed to either Ginger Jin, Department of Economics, University of Maryland, College Park, MD 20742; or Phillip Leslie, Graduate School of Business, Stanford University, Stanford, CA 94305-5015. Email: jin@econ.umd.edu; pleslie@stanford.edu.
} 


\section{INTRODUCTION}

A theoretical literature identifies several ways through which information to consumers may affect the behavior of firms and the efficiency of markets. ${ }^{1}$ With rare exception, the insight is typically that more information is better, which has led economists to support policies that seek to increase the amount of information available to consumers. ${ }^{2}$ Meanwhile existing empirical studies into the effects of information on firm behavior find small or negligible effects from increased information, casting doubt on the importance of such policies. We contend the failure is on the part of the empirical research, and is mainly due to the difficulty of observing exogenous variation in the amount of information available to consumers. In this study, we analyze a policy change that provides a context for evaluating the effects of increased product information on firms' product quality choices. In contrast to prior empirical studies into these issues, we find both statistically and economically significant increases in product quality due to an increase in information to consumers.

In December 1997 the Los Angeles County government passed an ordinance requiring restaurants to publicly display grade cards resulting from Department of Health Services (DHS) hygiene inspections. Restaurants had been subject to hygiene inspections for many years prior to the change, but the new regulation requires that the results of the inspections be revealed to consumers via a standard-format grade card to be prominently displayed in the window of each restaurant. To analyze the effects of the increased information we have constructed a panel dataset covering the period 1996 to 1998, with three key elements. First, we observe the outcome of every restaurant health inspection in Los Angeles county. Second, based on confidential sales tax data, we observe quarterly revenue for individual restaurants in Los Angeles county. Third, for all of California we observe the number of people admitted to hospital with food-related and non-food-related digestive disorders, in each month and in each 3-digit-zip code.

The central question of our study is: does an increase in the provision of information to consumers about the quality of firms' products, cause firms to improve the quality of their products? We first show that hygiene grade cards cause DHS inspection scores to increase by about five percent. We then verify the role of economic incentives to obtain higher scores when grade cards are issued. ${ }^{3}$ Prior to the grade cards, restaurant revenue is precisely insensitive to changes in hygiene scores. With grade cards, obtaining an A-grade causes revenue to be five percent

\footnotetext{
${ }^{1}$ The prior literature is discussed in Section II.

${ }^{2}$ Examples of mandatory disclosure policies in the U.S. include food labeling, energy efficiency of new home appliances, gas mileage of new cars and accounting disclosures for publicly traded firms. For an example of when information may be welfare-reducing, see Dranove et al [2000].

${ }^{3}$ With revenue data alone we are unable to infer the effect of the hygiene grade cards on restaurant demand, which would require price and quantity to be separately observed. However, showing a significant effect of the grade cards on revenue is sufficient to imply that demand is also responsive.
} 
higher than a B-grade, on average. But inspection scores may increase because restaurants make actual hygiene quality improvements, or because the grade cards cause inspectors to grade more leniently. To address this issue, we then show that grade cards cause a twenty percent decrease in foodborne illness hospitalizations. Furthermore, we show that this improvement in health outcomes is not fully explained by consumers substituting from poor hygiene restaurants to good hygiene restaurants. This implies the grade cards do indeed cause restaurants to improve hygiene quality.

There is also variation in our dataset that permits us to separately examine the effects of mandatory and voluntary disclosure. In some cities within Los Angeles County, the mandatory disclosure ordinance did not come into effect until some months after the initial implementation. ${ }^{4}$ In a city that has not adopted the ordinance, DHS inspectors nonetheless perform the same inspections and issue an official grade card, but it is at the discretion of each restaurant whether the grade card is displayed. This allows us to examine if the effects of the grade cards differ according to whether disclosure is mandatory or voluntary. We find statistically significant differences in the effect on hygiene quality, however, these differences are quite small in magnitude. This could be interpreted as evidence in favor of the argument that, given a standard format for revealing product quality, firms will voluntarily choose to disclose it. ${ }^{5}$ But an alternative explanation, in this case, is that firms were anticipating a change to mandatory disclosure in the future. Consequently, the estimates for the effects of voluntary disclosure of hygiene grade cards should be viewed with this caveat in mind.

In Section II we discuss the likely impacts of information disclosure. Los Angeles restaurant hygiene regulations are summarized in Section III, with an emphasis on describing the sources of exogenous variation we rely on in our analysis. The effects of the restaurant hygiene grade cards on hygiene inspection scores are analyzed in Section IV and the effects on revenue are analyzed in Section V. In Section VI we examine the effects of the grade cards on foodborne illness hospitalizations. Section VII concludes the paper.

\footnotetext{
${ }^{4}$ Almost all cities adopt the ordinance of mandatory disclosure before the end of 1998 . The reason why some cities delayed adoption of the ordinance is discussed in Section III.

${ }^{5} \mathrm{~A}$ literature on informational unraveling suggests that voluntary and mandatory disclosure yield the same outcome, as long as the information is verifiable with zero cost, as first studied by Grossman [1981] and Milgrom [1981]. See also the extensions in Jovanovic [1982], Farrell [1986], Fishman and Hagerty [1999] and Jin [2000b]. Fishman and Hagerty [1998] provide a review of disclosure incentives and unraveling. See Jin [2000a] and Mathios [2000] for empirical investigations of informational unraveling.
} 


\section{Potential Impacts of Information Disclosure}

In this section, we summarize some of the ways through which an increase in the provision of information to consumers is likely to impact the behavior of firms. In particular, we consider the possibility that the restaurant hygiene grade cards can mitigate an information asymmetry and may also have implications for the nature of competition among restaurants.

In the absence of restaurant hygiene grade cards, firms know significantly more about their level of hygiene quality than consumers do. ${ }^{6}$ As Akerlof [1970] shows, such an information asymmetry may prevent restaurants with good hygiene quality from profiting from it. The inability of consumers to identify good hygiene also inhibits any incentive for restaurants to invest in good hygiene quality. Consumers may, nonetheless, still go to restaurants, since the DHS helps to maintain a minimum standard of restaurants' hygiene. Other mechanisms, such as reputation, may assist restaurants to mitigate the problems arising from the information asymmetry.

Disclosure of restaurant hygiene grades mitigates the information asymmetry, allowing consumers to identify hygiene quality differences across restaurants. Demand at good hygiene restaurants may then increase, and demand at poor hygiene restaurants may be lower. These effects suggest prices may rise at good hygiene restaurants and fall at low hygiene restaurants. However, restaurants with poor hygiene may be able to improve their hygiene quality, at some cost. If the cost of increasing hygiene quality is less than the benefit from facing higher demand, restaurants may make hygiene improvements. If so, we expect the grade cards to cause an increase in average hygiene quality, with an associated decrease in the incidence of food-related illnesses.

The above discussion, in which the grade cards mitigate an asymmetric information problem, may be relevant even if each restaurant is a monopolist. There may be additional effects from mandatory disclosure when there are multiple restaurants in a market. In particular, by revealing differences between restaurants, grade cards may also serve to increase the degree of product differentiation in the market. ${ }^{7}$ Prior to grade cards, consumers may perceive relatively small differences in hygiene quality between restaurants, even though there are in fact large differences. By enhancing product differentiation among firms, the grade cards may soften the degree of price competition in the market, leading to a higher average price.

\footnotetext{
${ }^{6}$ Consumers may observe signals about restaurants' hygiene, so they are not completely uninformed. Also, restaurants may not fully know their hygiene, as there may be some aspects of hygiene beyond their control, such as the unobservable food contamination. But there is little doubt that consumers know much less about a restaurant's hygiene than the restaurant's manager.

${ }^{7}$ For models in which information serves to enhance product differentiation, see Nelson [1974] and Milgrom and Roberts [1986], among others.
} 
However, there may be a countervailing competitive effect to the increase in product differentiation. Disclosure of restaurant hygiene grades may serve to reduce search costs for consumers. Grade cards reduce the cost of learning whether an individual restaurant has good hygiene, and may encourage consumers to go to restaurants they otherwise would not have. By making consumers less captive to particular restaurants, this could promote competition between restaurants, providing incentives for lower prices, better food quality, or improved hygiene quality. ${ }^{8}$ If this effect is present, even among restaurants with the same hygiene quality grade, mandatory disclosure may cause lower prices and/or improved food quality.

Most prior empirical studies into the effects of information on firm behavior consider the specific question of whether price advertising causes lower prices. ${ }^{9}$ Generally speaking, these studies find small or insignificant effects. Milyo and Waldfogel [1999], for example, analyze a panel dataset with an exogenous change in advertising and find insignificant effects on prices. ${ }^{10} \mathrm{~A}$ study by Chipty and Witte [1998] provides an analysis of the effect of product quality information on product quality, as we do here. ${ }^{11}$ They find the quality of child-care services to be insensitive to the presence of a resource and referral agency (a free service providing information on the quality and prices of child-care firms).

There are a couple of reasons to believe we are likely to find significant effects on firm behavior from this particular change in information to consumers. ${ }^{12}$ In contrast to policy changes that introduce or eliminate prohibitions against advertising, mandatory disclosure of hygiene grade leaves restaurants with no choice of whether to display the information. ${ }^{13}$ Furthermore, firms have no choice about the method of disclosure, since a standard format is provided (ie. grade cards). It may also be the case that an increase in information about product quality is more likely to provoke a response from firms than an increase in information about prices. This is because, as Nelson [1970] suggests, while consumers may be uninformed about prices at particular firms, it may actually be easier to obtain price information than it is to obtain product quality information (prior to the grade cards). Clearly it is easier for a consumer to learn of a

\footnotetext{
${ }^{8}$ See Stigler [1961], Butters [1977] and Salop and Stiglitz [1977] for analyses of the pro-competitive effects from consumers having a lower cost of learning prices at specific firms. Nelson [1970] considers the case of consumers being uninformed about product qualities.

${ }^{9}$ Stigler [1961] provides the prediction that price advertising, by reducing search costs, lowers the mean and variance of the price distribution.

${ }^{10}$ See also Benham [1972], Devine and Marion [1979] and Kwoka [1984].

${ }^{11}$ There is also a literature that examines to what extent consumers' are responsive to the increased provision of product information. For example, a number of studies examine the effects of product labeling regulations on consumer demand. Teisl and Roe [1998] survey the studies of labeling issues. The focus of our study is firm decision-making in the face of an increased provision of information to consumers.

${ }^{12}$ This is aside from the fact that we have a large number of observations and an exogenous change in information, which of course also helps to uncover significant effects.

${ }^{13}$ As Milyo and Waldfogel [1999] explain, the policy change they study is one in which firms are no longer prohibited from price advertising. In response, not all firms choose to do so, and even at the firms that do, prices of only select products are advertised.
} 
restaurant's prices, by simply looking at the menu, than it is to learn of the restaurant's hygiene quality in the absence of a posted grade. Hence, the grade cards may eliminate a substantial search cost for consumers.

Our goal is to see if there is evidence of any change in behavior by firms to the increase in information to consumers. From the above discussion, the overall effect of disclosure of restaurant hygiene grade cards on prices is, a-priori, ambiguous. As indicated in the introduction, our dataset does not include restaurant prices, so we are unable to empirically resolve this ambiguity. ${ }^{14}$ Nevertheless, each of the above effects of disclosure are based upon consumers becoming more responsive to restaurant hygiene quality, than before there were grade cards. As we explain below, our analysis of the effects on revenues is sufficient to verify the responsiveness of demand to the grade cards. Importantly, the likely effect on hygiene quality and health outcomes seems clear - grade cards should cause an increase in average restaurant hygiene and a decreases in illnesses.

\section{Summary of the Policy Change}

According to the Census Bureau's 1997 Economic Census, full-service restaurants and limitedservice eating places employed almost 7 million people in the U.S., or roughly 5 percent of total employment. Total annual revenue for these firms was $\$ 220$ billion. In Los Angeles County the industry employed 207,000 people, with annual revenues of $\$ 7.9$ billion. The DHS randomly inspects all restaurants in Los Angeles county and our data contains every inspection from January 1, 1996, to December 31, $1998 .{ }^{15}$ The first column of Table I shows the number of restaurants that are subject to DHS inspections in each quarterly period (which is different from the number of inspections). During the period of our data the number of restaurants rises from 19,590 to 22,652. The second column provides the average hygiene score for all inspections conducted in each quarter. A point to note is the stability of the average score around 75 percent for the first half of the period, followed by a dramatic rise to 90 percent in the second half.

The inspection data from the DHS is matched to sales tax data from the California State Board of Equalization (SBE). The matching process is imperfect which reduces the number of observations. ${ }^{16}$ Columns 3 and 4 of Table I show the number of restaurants the SBE successfully matches with the DHS data. After matching the total number of restaurants in our sample is reduced by approximately 28 percent. From the matched data, we then eliminate restaurants for

\footnotetext{
${ }^{14}$ Actually, we do describe an analysis of restaurant price index data in Section V, but these results are merely suggestive.

${ }^{15}$ Random timing of restaurant inspections is an important source of exogenous variation for our analysis.

${ }^{16}$ As there is no common numerical identifier that DHS and SBE have in their data, matching is done on the basis of establishment name and address. Matching fails in cases where no common address or name is found.
} 
which we do not observe consecutive tax payments, further reducing the sample to 57 percent of all restaurants in Los Angeles county. This is because we do not know the reason for the missing payments, which raises a question as to whether the payment in the following quarter includes the missing payment of the prior quarter. Hence all results reported in this paper are based on the sample of 13,544 restaurants. There are only minor differences in the average hygiene scores between the full sample and the reduced sample, as shown in Table I, suggesting that the selection is unbiased for our purposes. Moreover, in our analysis of the effects on hygiene quality, below, we obtain very similar estimates whether we use the the full 23,921 restaurants or the sample of 13,544 restaurants, providing even stronger evidence of an unbiased sample.

The key feature of our data is the introduction of hygiene grade cards. We consider this to be an exogenous change in regulation due to the fact that it was rapid and unanticipated. The timing of events is as follows:

- November 16-18, 1997 - over three consecutive evenings CBS 2 News on the Los Angeles based Channel 2000 aired a three-part report titled "Behind the Kitchen Door". The report used hidden cameras to show viewers unsanitary restaurant kitchens.

- December 16, 1997 - in response, the Los Angeles County Board of Supervisors unanimously voted in favor of the grade card ordinance.

- January 16, 1998 - the ordinance came into effect at the county-level.

Incorporated cities within the county, however, are free to adopt the ordinance or not. ${ }^{17}$ Unincorporated cities, and some incorporated cities, adopted the ordinance immediately, while others took longer and did not adopt before the end of 1998. Importantly, whether a restaurant is located in a city that adopts the ordinance or not, all restaurants are issued with a grade card at any inspection after January 16, 1998. For restaurants located in cities that have not adopted the ordinance, restaurants have complete discretion whether the card is displayed or not.

Table II shows the extent of adoption on a quarterly basis during 1998 for the restaurants in our sample. Since it may take several months for a restaurant to receive its first inspection after January 16, 1998, Panels A and B distinguish between the number of restaurants in cities that have adopted the regulation, and the number of restaurants subject to each of the three mutually exclusive and exhaustive regimes. "Voluntary disclosure without standard-format" refers to restaurants who have not yet received an inspection after the grade cards are introduced. These restaurants have no grade card, so it is irrelevant whether their city has adopted the ordinance or not. "Voluntary disclosure with standard-format" applies to restaurants that have received a grade card (or equivalently, have been inspected at least once after January 16, 1998), but are located in a city that has not adopted the ordinance at that point in time. Finally, "mandatory

\footnotetext{
${ }^{17}$ There are 88 incorporated cities in Los Angeles county.
} 
disclosure" applies to restaurants that have been issued a grade card and are required to display it. We observe inspection dates and city adoption dates, hence the table is constructed by aggregating daily observations to the quarterly level.

As shown in Panel A of Table II, for the first quarter of 1998, less than 5 percent of restaurants are located in cities that have adopted mandatory disclosure of grade cards. This number rises to 80 percent by the end of 1998. Panel B displays a more relevant summary of the frequency of the three policy regimes. In the first quarter of 1998, roughly 85 percent of restaurant-days have no disclosure possibility. This number rapidly falls to 4 percent in the fourth quarter. Also in the fourth quarter of 1998, notice that 34 percent of restaurant-days fall under voluntary standard-format disclosure, with the majority (62 percent) falling under mandatory disclosure.

The different dates at which cities adopt the mandatory disclosure ordinance, as depicted in Table II, is another source of variation we exploit in our analysis. We believe this variation in the timing of city adoption to be exogenous for the following reasons. The fact that most cities which did not initially adopt, eventually do adopt within 12 months, suggests it is more likely due to bureaucratic delays rather than the influence of restaurants. To verify this intuition we examine whether the timing of ordinance adoption by each city is correlated with characteristics of restaurants in the city. To do so, we estimate a duration model in which the dependent variable is the probability of a city adopting the ordinance at a point in time conditional on having not adopted so far. The explanatory variables include characteristics related to restaurants in the city (restaurant revenue per person, median restaurant revenue, dispersion of restaurant revenue and proportion of restaurants with hygiene scores above 90), and city demographics (number of households in the city, median household income, children per household, proportions of females, blacks, Asians, and Hispanics). ${ }^{18}$ While not reported in a table, the results support our intuition in favor of exogenous city adoption dates - estimated coefficients on the restaurant characteristics are insignificantly different from zero. ${ }^{19}$

During the three years covered in our data the average number of inspections per restaurant per calendar year has changed from around 1.9 to over 2.1, with some restaurants inspected more than four times per year. Over 85 percent of inspections are regular random inspections. However there are also complaint-initiated inspections and owner-initiated inspections, both of which are identified in the data. ${ }^{20}$ Beginning on January 16, 1998, at the end of an inspection

\footnotetext{
${ }^{18}$ Demographic variables are obtained from the 1990 population census. Restaurant characteristics are for the period before the CBS news story that provoked the grade card policy. There are 83 observations (cities) in the estimation.

${ }^{19}$ For the coefficients on restaurant revenue per person, median restaurant revenue and proportion of restaurants with hygiene scores above 90 the p-values are greater than 0.3 , while for revenue dispersion the p-value is slightly above 0.1 .

${ }^{20}$ The DHS will inspect a restaurant in response to a single customer complaint. The DHS introduced ownerinitiated inspections in the last half of 1998 out of concern for the fact that a restaurant may be branded with
} 
each restaurant is issued a grade card: "A" (90-100 percent), "B" (80-89 percent), "C" (70-79 percent), or if the score is less than 70 percent the restaurant is issued a card that reports the actual score. ${ }^{21}$ In cities that have adopted mandatory disclosure, the signs are required to be in clear view for customers. A restaurant is closed by the DHS if (i) two consecutive inspections result in a score below 60 percent, or (ii) if there is a severe hygiene problem (such as an infestation).

There have been a few changes in the inspection scoring criteria during our sample which we incorporate in the analysis below. Until July 1, 1997, the inspections included both an objective and a subjective element. The subjective aspect was the inclusion of an "establishment status score" which was one of excellent (zero points deducted), good (5 points), average (20 points), fair (30 points) or poor (40 points), and was intended to be the inspector's overall evaluation of the hygiene status of the restaurant. Since July 1, 1997, the subjective component of the assessment has been removed and inspections are now objective in nature. Beginning with a score of 100, pre-specified points are deducted for each violation. For example, a food temperature violation results in a 5 point deduction, evidence of cockroaches results in a 3 point deduction, a functioning but unclean toilet results in a 2 point deduction, and improperly washed/sanitized eating utensils result in a 5 point deduction. A minor change in the inspection scoring was again made on March 18, 1998, to add in a small number of additional potential violations. Because this change is only two months after grade cards have begun to be issued, observed changes in hygiene scores in 1998 may be partly due to the introduction of grade cards, and partly due to the change in assessment criteria. In the analysis below, we attempt to distinguish the two effects by exploiting the two month time difference between the changes.

In this section we have described some important aspects of the regulatory change with particular emphasis on the variation in the data that facilitates our analysis that follows. To summarize, there are three main sources of exogenous variation: (i) the unanticipated introduction of grade cards to be issued to every restaurant in Los Angeles county following their next inspection regardless of whether disclosure is mandatory or voluntary; (ii) different cities within the county adopt the ordinance for mandatory disclosure at different points in time; and (iii) individual restaurants are randomly inspected at different points in time. ${ }^{22}$ In the next section we analyze the effects of the grade cards on DHS hygiene inspection scores.

a low grade for several months for violations that can be corrected in a short space of time. The DHS allows each restaurant to request an inspection up to a maximum of once per year, for which they must pay the stated marginal cost of the inspection of $\$ 161$.

${ }^{21}$ We have placed a selection of photos of the grade cards in restaurant windows on the web to give an idea of what the consumer sees: www.stanford.edu/ pleslie/restaurants

${ }^{22}$ Which particular source of variation identifies the effect of interest is different in different regressions. 


\section{The Effect of Hygiene Grade Cards on Hygiene Scores}

Restaurants offer products whose characteristics include quality, food type and geographic location. Quality itself involves many dimensions: food quality, service quality and hygiene quality. In this study we examine restaurants' hygiene quality. The stated goal of the DHS introducing grade cards was to increase hygiene quality levels in Los Angeles restaurants. In this section we analyze the restaurant-level hygiene inspection data to determine whether hygiene scores have improved due to the grade cards. In doing so we also examine whether the effect of the grade cards on inspection scores differ under mandatory or voluntary posting of grade cards. In principle, the inspection scores are an accurate and standardized measure of restaurant hygiene quality. In the current section we assume this is the case. However, as noted in the introduction, there is the possibility that the grade card policy induced a change in the grading behavior of inspectors. Such a change would confound the use of inspection scores as a universal measure of hygiene quality and is addressed in Section VI.

Figure I shows the changing distribution of hygiene inspection scores over time, also indicating the timing of the two assessment changes and the introduction of grade cards. Prior to July 1997 the distribution appears stable with a median around 75. The assessment change in July 1997 results in an increase of about 10 points in the median and reduced dispersion. In November 1997 the distribution shifts down, presumably a response by inspectors to the television news story. The introduction of the grade cards are followed by two months of increasing scores before the second assessment change which is also followed by continued increases. By the end of 1998 the figure shows dramatically reduced dispersion relative to 1996, with approximately 70 percent of restaurants obtaining scores above 90 percent. The assessment change in March 1998 is a relatively minor one, but we can not be certain the observed increases in hygiene scores in 1998 are not at least partially due to this. In the regression analysis we include dummy variables

for each of the assessment changes. Finally, we note that in Figure I there is no apparent time trend or seasonality in hygiene scores.

The estimating equation of primary interest is

$$
h_{i t}=\alpha_{i}+\beta_{1} m_{i t}+\beta_{2} v_{i t}+\gamma_{1} c_{1 t}+\gamma_{2} c_{2 t}+\epsilon_{i t}
$$

where $h_{i t}$ denotes the hygiene inspection score obtained by restaurant $i$ at time $t, m$ equals one if it is mandatory to post a grade card for the inspection, $v$ equals one if it is voluntary to post a grade card for the inspection, $c_{1}$ and $c_{2}$ are dummies for the different inspection score criteria after July 1, 1997, and March 18, 1998, respectively. The $\alpha, \beta$ and $\gamma$ terms are coefficients to be estimated and $\epsilon$ is a residual. In addition to estimating equation (1), we estimate an equation in which the restaurant fixed-effects $\left(\alpha_{i}\right)$ are replaced by observable restaurant characteristics 
$\left(X_{i} \alpha\right)$. We also include a city-level random-effect to obtain conservative standard errors. ${ }^{23}$

In this regression an observation is a restaurant inspection. ${ }^{24}$ After the county passed the grade card ordinance all restaurants are issued a grade card following an inspection, so there is no control group of restaurants undergoing inspections by the DHS at the same time which are not issued with grade cards. Identification of the effects from grade cards is therefore primarily due to time series variation in whether grade cards are issued. However, at the same point in time in some cities the posting of grade cards is voluntary while in other cities the posting is mandatory, providing cross-sectional variation which helps to separately identify the effects of mandatory and voluntary disclosure. In the previous section we explained why it is reasonable to consider both kinds of variation as exogenous. To the extent that one may still be concerned about possible bias in this regression due to endogeneity of the timing when cities switch from voluntary to mandatory disclosure, note that we include restaurant fixed-effects to control for time-invariant restaurant (and hence also city) characteristics which preclude some sources of bias. If there is a bias due to endogenous city ordinance adoption it must be because timevarying city characteristics contained in the residual are correlated with the timing of ordinance adoption. Two pieces of evidence argue against this possibility. First, the finding in the previous section that time-invariant characteristics of restaurants in each city are uncorrelated with the timing of city adoption suggests any time-varying characteristics of restaurants may also be uncorrelated. Second, a leading example of the sort of correlation that could induce a bias would be if the rate of change of hygiene quality in each city is correlated with the timing of city ordinance adoption, which we find not to be the case. ${ }^{25}$

Table III reports the results from OLS estimation of equation (1). All coefficients are highly significant and there is no substantial difference when observable restaurant characteristics or restaurant fixed-effects are included, so we focus on the fixed-effects results here. The coefficient on the Inspection Criteria II dummy reveals the change in assessment criteria in July of 1997, prior to the introduction of grade cards, caused hygiene scores to increase by an average of 8.09 points. We presume this coefficient identifies a purely nominal change in scoring with no change in the actual hygiene quality of restaurants. The estimate for the nominal effect on hygiene scores from changing to Inspection Criteria III in March of 1998, after the introduction of grade cards, is an average increase of 2.33 points. $^{26}$

\footnotetext{
${ }^{23}$ See Kézdi [2002] for a discussion of the use of cluster estimators for obtaining robust standard errors in the presence of possible serial correlation.

${ }^{24}$ In the revenue regressions of the next section an observation is a restaurant in a quarter.

${ }^{25}$ Specifically, we regress the timing of city adoption on the average rate of change of hygiene scores in each city prior to the CBS news story and find the estimated coefficient is insignificant (p-value greater than 0.3).

${ }^{26}$ To compute the net effect from changing to Inspection Criteria III, subtract the coefficient on Inspection Criteria II from the coefficient on Inspection Criteria III.
} 
The estimated effect from mandatory disclosure of hygiene grade cards is an average increase in inspection scores of 4.40 points, or 5.3 percent. To emphasize the magnitude of the effect, this is equal to 0.4 of a standard deviation of the hygiene score distribution. ${ }^{27}$ This positive and significant estimate is evidence in favor of increased information to consumers causing quality improvements by firms.

The estimated effect from voluntary disclosure of hygiene grade cards is an average increase in hygiene scores of 3.25 points, or 3.9 percent. With 90 percent confidence we reject the hypothesis of equal coefficients on the two disclosure dummies. ${ }^{28}$ But, while the coefficients are statistically different, the magnitude of the difference is only 1.15 points, which is small in comparison to the levels of these effects. As previously noted, caution should be used when interpreting the similarity between the effects of mandatory and voluntary disclosure. On the one hand, this may support the case for informational unraveling, in which firms' choose to reveal information about their quality when they are able to credibly do so. But, on the other hand, the experiment in the data is not ideal, as restaurants may be anticipating the change to mandatory disclosure in the future and begin preparations in advance. Consequently, we do not believe these results should be taken as strong evidence, either for or against unraveling.

To check the robustness of the estimates reported in Table III we considered a few variations on the reported regression. First, we transformed the dependent variable using a logit function which bounds the predicted scores to lie between zero and $100 .^{29}$ There were no significant changes in the estimated effects. However the logit transformation did reveal statistically insignificant differences between the effects of mandatory and voluntary disclosure. Second, we separately re-estimate after excluding (i) restaurants that cease making sales tax payments at some time during 1998, which is rough indication these restaurant closed after the grade cards were introduced - this can shed light on the extent to which hygiene improvements are obtained by improving incumbents or by a process of entry and exit); (ii) owner-initiated inspections; and (iii) complaint-initiated inspections. ${ }^{30}$ In each case the number of excluded observations is few and in each case the estimated coefficients did not change in any significant way. Third, to investigate the possibility that the effects on hygiene quality from grade cards are gradual, perhaps even to such an extent that the full effects are not apparent by the end 1998, we also

\footnotetext{
${ }^{27}$ The standard deviation for the distribution of hygiene scores from inspections conducted between July 1 , 1997, and January 15, 1998, was 11.29. As verification of the statistical significance, a simple test of the difference in means between the distribution of scores under Inspection Criteria II without grade cards, and Inspection Criteria II with mandatory grade cards, rejects equality with 99.99 percent confidence.

${ }^{28}$ There is a positive covariance of 3.18 between the coefficients on the mandatory and voluntary disclosure dummies, which is why we find the difference to be significant even though they are fairly close to each other given the standard errors.

${ }^{29}$ Specifically, we transform the score $h$ using $\ln (h /(100-h))$.

${ }^{30}$ Owner-initiated inspections take place, if at all, shortly following a regular inspection. These are cases when the owner believes they have received a low grade due to violations that can be quickly remedied. There are relatively few owner-initiated inspections in 1998.
} 
estimate the average effects of grade cards separately for each quarter period in 1998. While not shown in a table, we find that average effects, from both mandatory and voluntary disclosure, in the second quarter of 1998 are significantly higher than in the first quarter, and the effects in the third and fourth quarter are not significantly different from the second quarter. ${ }^{31}$ These results suggest the effects on hygiene from the grade cards are realized fairly rapidly.

\section{The Effect of Hygiene Grade Cards on Revenue}

In the preceding section we showed that the increased provision of information about hygiene quality causes an increase in average hygiene scores of restaurants, and that this is true whether disclosure of the information by restaurants is voluntary or mandatory. If consumers do not care about the grade cards, either because there is no new information contained in them or because they do not care about health inspection scores, this would cast doubt on the role of economic incentives underlying the observed increase in hygiene scores. ${ }^{32}$ Perhaps it is restaurant owner/manager pride, other psychological reasons or simply a quirk of the inspection regime in Los Angeles. We may then be skeptical of grade cards as an effective policy tool in other locations or contexts. For these reasons it is valuable to examine evidence of whether consumer demand is responsive to the grade cards, as we expect it should be.

Our dataset includes individual restaurants' quarterly revenue. Revenue data alone is insufficient to estimate a demand function. However revenue data alone is sufficient to verify that demand is responsive to the new information, for the following reason. Suppose we observe that restaurant revenue is sensitive to the hygiene grade cards. Also suppose, in contradiction to our claim, that demand is not responsive to the grade cards. Then it must be that there was a change in costs which led to a change in equilibrium output and prices, and therefore a change in revenue. But, the policy of introducing grade cards does not require restaurants to incur any cost changes. Restaurants will only choose to incur cost changes if demand is responsive to the cost changes. Therefore, if grade cards cause a change in revenue, this implies consumers are responsive to the grade cards.

A problem arises when analyzing the effects on revenue because the revenue data is quarterly, while inspections occur on a specific date within a quarter. In any given quarter in 1998, a restaurant may fall under multiple policy regimes. For example, on April 15 a restaurant may receive its first inspection since the grade cards were first introduced in January, and suppose

\footnotetext{
${ }^{31}$ This is also graphically evident in Figure I.

${ }^{32}$ Whether the observed increases in hygiene scores are due to actual hygiene improvements by restaurants and/or changed inspector behavior, both of these explanations rely on consumers being sensitive to the grade cards.
} 
on May 1 the city in which the restaurant is located adopts the county ordinance, following which the restaurant happens to be inspected again on June 1 for which disclosure is then mandatory. In this case, the disclosure dummies take on values between zero and one, reflecting the proportion of time during that quarter that each regime applied. A similar problem arises when a restaurant starts a quarter with a score of 75 percent, say, is then inspected during the quarter and receives a score of 95 percent, say. In such cases we assign the days-weighted average score to the restaurant for that quarter and determine a grade for that quarter based on the weighted average score. In each of these examples we effectively assume that revenue is uniformly distributed over each quarter.

To analyze the effect of the increased information on restaurant's revenue we estimate the following equation for the $\log$ of revenue obtained by restaurant $i$ in quarter $t$ :

$$
\ln \left(r_{i t}\right)=\alpha_{i}+\tau_{t}+\sum_{j} \beta_{j} h_{i j t}+\sum_{k} \gamma_{k} g_{i k t}+\sum_{j} \sum_{k} \delta_{j k} h_{i j t} g_{i k t}+\epsilon_{i t}
$$

where

$$
\begin{aligned}
h_{i t} & =\left\{h_{i 1 t}, \ldots, h_{i 4 t}\right\} \equiv\left\{A_{i t}, B_{i t}, C_{i t}, D_{i t}\right\}, \quad \text { and } \\
g_{i t} & =\left\{g_{i 1 t}, g_{i 2 t}\right\} \equiv\left\{m_{i t}, v_{i t}\right\} .
\end{aligned}
$$

The variables for the disclosure regimes of mandatory disclosure $(m)$ and voluntary disclosure $(v)$ are no longer dummy variables equal to either zero or one. Instead, because we aggregate to the quarterly level, these variables take on continuous values between zero and one. The variables in $h$ are for hygiene grades (eg. $A$ for A-grade), where $D$ corresponds to all scores below 70, and also take on continuous values between zero and one. In the estimation we exclude $A$. As shown in equation (2) we include restaurant fixed-effects $\left(\alpha_{i}\right)$ and a full set of quarterly dummies $\left(\tau_{t}\right)$. As in the hygiene regressions, above, we also include city-level random-effects to provide conservative estimates of the standard errors that are robust to the presence of possible serial correlation. ${ }^{33}$

In the revenue regressions an observation is a restaurant in a quarter. Since we observe restaurant revenue regardless of whether the restaurant was inspected in that quarter or whether the restaurant has been issued a grade card, restaurants that have not yet received grade cards serve as a control-group. The variation in grade cards in the cross-section is exogenous because the DHS ensures the timing of individual restaurant inspections is random. The effects on revenue from the grade cards are therefore identified from a combination of time series and cross-sectional variation.

\footnotetext{
${ }^{33}$ We also estimated the revenue regression using observable restaurant characteristics instead of restaurant fixed-effects and found no interesting differences so these results are not reported.
} 
If a restaurant owner has multiple restaurants in a single city, the tax payments for these restaurants are made to a single account with the government. ${ }^{34}$ In these cases we have no way of knowing how to assign revenue to the different restaurants owned by the person in a given city, though we do observe a binary variable identifying when these instances occur. We perform the revenue regression on the sample including these joint-account restaurants and on a sample in which they are excluded. The results differed only slightly between the two samples suggesting the smaller sample is not biased. We therefore report results for the smaller sample where we always observe individual restaurant revenues.

Table IV reports OLS estimates for the specification shown in equation (2). ${ }^{35}$ The first point to note from these estimates is that when there are no grade cards, restaurant revenue is unaffected by changes in hygiene quality. ${ }^{36}$ This is evident from the coefficients on B-grade, Cgrade and D-grade which are insignificantly different from zero (even with rather small standard errors). The estimated coefficient on the mandatory disclosure dummy implies the effect from mandatory posting of grade cards for an A-grade restaurant is a 5.7 percent increase in revenue compared to before the introduction of grade cards. Since average annual revenue for restaurants in our sample in 1997 is roughly $\$ 260,000$, the absolute magnitude of the effect is nearly $\$ 15,000$. Revenue for B-grade restaurants increases by about 0.7 percent due to the introduction of mandatory grade cards, or 4.97 percent less than the effect for A-grade restaurants. For Cgrade restaurants under mandatory disclosure the net effect is a 1 percent decrease in revenue. These results confirm the presence of economic incentives underlying the observed increases in hygiene quality.

The effect of voluntary disclosure for A-grade restaurants is estimated to be an increase in revenue of 3.3 percent. This is 2 percent less than the effect under mandatory disclosure, but it does reveal an economic gain from disclosure for restaurants with high quality hygiene. The net effects of voluntary disclosure for B-grade and C-grade restaurants are insignificantly different from the effect from an A-grade with voluntary disclosure, though the point estimates indicate less of an increase than for an A-grade. Why are the effects on revenue from voluntary disclosure so much smaller in magnitude than the effects from mandatory disclosure? The reason may be that the details of the regulatory change were not well explained to the residents of Los Angeles county. Media coverage at the time the grade cards were introduced emphasized

\footnotetext{
${ }^{34}$ If the restaurants owned by the same person are in different cities then tax payments are made to different accounts, allowing us to observe individual restaurant revenue.

${ }^{35}$ Note, even though hygiene scores (and hence grades) endogenously increased, this does not give rise to an endogeneity problem in the sense of biasing the estimated coefficients, because we also include as regressors the policy-regime dummies which cause the hygiene changes. In other words, the assumption that hygiene grades are uncorrelated with the residual is valid.

${ }^{36}$ Since the regression includes restaurant fixed-effects, it may be that restaurants with consistently high hygiene quality earn high revenue, for example. However the estimates reveal that increasing hygiene quality at a particular restaurant has no impact on revenue at that restaurant (before the introduction of grade cards).
} 
the mandatory disclosure requirement, without explaining that for many cities disclosure was in fact voluntary. Restaurants located in cities with voluntary posting were able to take advantage of the misconception that the absence of a posted grade card must be because the restaurant has not yet been inspected since the grade cards were introduced. Hence, restaurants obtaining a Bgrade may choose not to post the grade and consumers incorrectly believe the restaurant is likely to be of A-grade standard. This argument is also consistent with the estimates showing the effects of A-grade, B-grade, C-grade and missing-grade under voluntary disclosure are insignificantly different from each other.

The estimated effects on revenues imply that demand is responsive to restaurant hygiene grade cards. In Section II we discussed the possibility that prices may also change in the face of the new information, though the sign of this effect is ambiguous. ${ }^{37}$ We may obtain an indication of the possible effect on price by examining the Bureau of Labor Statistics monthly price index for "food away from home" in Los Angeles, Riverside and Orange counties combined. ${ }^{38}$ We compare this price index with the price indices for the same category in other regions, or with other classes of goods in the same region, over the period January 1991 to February 2001. ${ }^{39}$ Controlling for region or category effects and monthly dummies, we find statistically significant decreases in the price index for restaurants in Los Angeles at the time the grade cards are introduced, whether compared to restaurant price indices in other regions, or price indices for other retail goods in Los Angeles. ${ }^{40}$ This suggests a dominant effect of the grade cards may be to intensify competition among restaurants, possibly due to lower search costs. ${ }^{41}$

\footnotetext{
${ }^{37}$ For A-grade restaurants, we estimate the grade cards cause an increase in revenue. But, since revenue equals price times quantity, the only thing we are sure of is that price and quantity have not both decreased for these restaurants.

${ }^{38}$ The data and supporting documentation is available from http://stats.bls.gov/cpihome.htm. Unfortunately a price index is not available for Los Angeles county alone, however Los Angeles has more than twice the combined population of Riverside and Orange counties.

${ }^{39}$ Comparison regions are: San Francisco-Oakland-San Jose counties, Chicago-Gary-Kenosha counties, and N.Y.-Northern N.J-Long Island counties. Comparison goods categories are: food at home, alcoholic beverages and all items.

${ }^{40}$ Details of the analysis are available on request from the authors.

${ }^{41}$ We estimate the average effect of the grade cards on revenues is positive and the average effect on prices is negative. This implies the effect of grade cards on output must be positive. Some verification of this comes from analyzing monthly, industry-specific, region-specific, employment data from the BLS. We compare employment in restaurants in Los Angeles with employment in restaurants in other counties, as well as employment in other retail industries in Los Angeles. Assuming employment is correlated with output, we find the grade cards also have a positive effect on output. Again, details of the analysis are available from the authors.
} 


\section{Vi. Hygiene Improvements and/or Changed Inspector Behavior?}

The central question of our study is whether an increase in information about product quality to consumers causes firms to improve product quality? We show above that the introduction of restaurant hygiene grade cards cause an increase in restaurant health inspection scores. We also show above that prior to the hygiene grade cards, consumers are insensitive to restaurants' hygiene changes, and when there are posted hygiene grade cards, consumers are responsive to the grades. One possibility is that the higher scores are obtained as a result of restaurants making hygiene quality improvements in response to the new incentives. If so, then we would answer the above question affirmatively.

There is, however, another possible explanation for the increased hygiene scores under which there is no improvement in hygiene quality by restaurants. It is possible the grade cards cause inspectors to modify their grading decisions, with little or no change in restaurants' actual hygiene quality. For example, inspectors may feel bad about giving a B-grade knowing that the restaurant will lose customers as a result. ${ }^{42}$ An obvious analogy is a professor faced with a student who has barely missed an A for the class, then decides to bump up the score to an A, out of concern for the student's future and knowing the imperfections of exam grading.

A question arises as to why rational consumers would respond to the restaurant hygiene grade cards if there are no changes in actual hygiene? The answer could be that grade cards facilitate sorting across restaurants. As long as the grade cards provide an informative signal about restaurants' heterogeneous true hygiene quality, then consumers may use this information to sort high quality restaurants from low quality restaurants. The point is that the presence of economic incentives to obtain an A-grade card, as verified by the above revenue analysis, may be consistent with either explanation for the observed increase in inspection scores.

In this section we therefore address the question: are the observed increases in hygiene scores due to restaurant hygiene improvements, changed inspector behavior, or some combination of both? There are two subsections. In the first subsection we present evidence suggesting the grade cards probably do lead to a change in the behavior of inspectors. In the second subsection we provide evidence suggesting there are also significant hygiene quality improvements. We conclude from this that the grade cards cause a combination of changed inspector behavior and actual hygiene improvements. Thus the increased provision of product quality information does cause an increase in firms' product quality.

\footnotetext{
${ }^{42}$ Other possible explanations for changed inspector behavior include bribery. Though we have no evidence this is any more likely than inspectors simply feeling bad about giving low grades. In fact the DHS conducts random follow-up inspections as a check on the possibility of inspectors being bribed or manipulating scores, which would mitigate this behavior to some extent.
} 


\section{A. Evidence of Changed Inspector Behavior}

The most compelling indication of a change in the behavior of inspectors due to the introduction of hygiene grade cards comes from the change in the shape of the distribution of inspection scores. Figure II depicts the empirical distributions of hygiene inspection scores under the three regimes of no grade cards, mandatory disclosure of grade cards and voluntary disclosure of grade cards. ${ }^{43}$ When there are no grade cards the distribution of scores is very smooth, much as one might expect. In contrast, Figure II reveals a dramatic spike in the score distributions for both mandatory and voluntary disclosure at the score of $90 .{ }^{44}$ We can think of two possible explanations for the spike. On the one hand, since grade cards do not distinguish between a low-A and a high-A score, there is no benefit for restaurants to improve hygiene beyond obtaining a score of 90. Consequently if restaurants face little uncertainty over the score they will obtain from an inspection and it is costly to improve hygiene, then we would expect to observe a spike in the hygiene distribution at 90 .

A second, and undoubtedly more plausible, explanation for the spike is that inspectors choose to ignore a violation in order to help restaurants that are only a point or two below obtaining an A-grade. It seems fairly clear that for some restaurants that would otherwise have received a score of 89 the inspector now chooses to give a score of 90 . But it is not clear whether restaurants obtaining other scores, such as 91 or higher, are also being given higher scores than they would have if there were no grade cards. Since the grade cards do not distinguish a score of 90 from a score of 91 or higher, it is not obvious that an inspector would inflate the inspection score to 91 or higher, though we cannot rule out this possibility. In any event, the spiking strongly suggests that grade cards induce a change in the behavior of inspectors that leads us to question whether higher scores are due to restaurants making actual hygiene improvements.

On a different note, another interesting feature of Figure II is the remarkable similarity in the score distributions for mandatory and voluntary disclosure. Particularly given the dramatic changes in these distributions compared to when there are no grade cards. The policy of mandatory posting of grade cards seems to make little difference to a policy of issuing grade cards and allowing firms the discretion of whether their grade card is displayed.

\section{B. Evidence of Actual Hygiene Improvements}

We divide our analysis of the evidence of actual hygiene improvements into two stages. First, we examine data concerning the occurrence of food-related illnesses. In the second stage we

\footnotetext{
${ }^{43}$ We show the distributions only for the interesting region of scores which are scores above 65 . The figure is no different to a set of three histograms - the lines are unsmoothed non-parametric densities.

${ }^{44}$ There is also a spike at 80 that is much smaller than the spike at 90 .
} 
consider an alternative specification for the hygiene score analysis and analyze specific hygiene violations by restaurants.

\section{Evidence of a Decrease in Food-Related Illnesses in Los Angeles}

If the only effect of grade cards is to change inspector behavior, then we may not expect to see any reduction in the incidence of food-related illnesses in Los Angeles. A finding that grade cards cause a significant decrease in the number of food-related illnesses may then be evidence of actual hygiene improvements by restaurants. In California, the Office of Statewide Health Planning and Development (OSHPD) makes available relatively disaggregate hospital admission data. Specifically, from this data we observe the principal diagnosis, month of admission and 3-digit-zip code for every hospital admission in California in the years 1995 to 1999. A particular principle diagnosis may occur due to foodborne transmission or not and the OSHPD data does not indicate whether the illness is food-related. However, certain principal diagnoses are almost always due to foodborne transmission which allows us to analyze the effect of the grade cards on health outcomes, as measured by hospital admissions. ${ }^{45}$

The OSHPD data, however, is not at the restaurant level, so we are unable to measure the probability of a consumer becoming ill at any individual restaurant. An implication of this is that a decrease in the number of food-related illnesses in Los Angeles corresponding with the introduction of the grade cards, may be due to consumers substituting demand away from low hygiene to high hygiene restaurants, even though restaurants make no actual hygiene improvements. In other words, grade cards cause an increase in the mean of the distribution of restaurant hygiene weighted by the number of consumers going to each restaurant. This sorting effect alone may lead to reduced incidence of food-related illness. A second issue also complicates the analysis of food-related illnesses. The DHS conducts hygiene inspections of every establishment that sells food, whether pre-packaged, prepared, or otherwise. This includes video rental stores that sell packaged candy as well as supermarkets, and these establishments are also issued with hygiene grade cards. It could be, therefore, that hygiene improvements at supermarkets due to the introduction of grade cards, lead to fewer cases of people becoming sick from eating at home. ${ }^{46}$

From the point of view of improving public health, if there is a decrease in food-related illness

\footnotetext{
${ }^{45}$ We have no data on the number of food-related illnesses that do not result in a hospital admission. We can only speculate that a decrease in hospital admissions for food-related illnesses suggests a decrease in food-related illness more generally. But even if the only effect is on admissions, this would still be evidence of actual health improvements.

${ }^{46}$ There may also be consumer substitution from supermarkets (ie. eating at home) to better hygiene quality restaurants, which may also explain reduced illnesses without restaurants changing their behavior. We also take this into account in our analysis.
} 
because of the hygiene grade cards, it may be irrelevant whether this is because restaurants improve their hygiene, supermarkets improve their hygiene, or because of enhanced sorting by consumers. ${ }^{47}$ For our purpose, however, we seek evidence of actual hygiene improvements by restaurants. In the analysis below, we seek to separate the three effects of (i) restaurant hygiene improvements, (ii) supermarket, or home cooking, hygiene improvements, and (iii) consumer sorting towards good hygiene restaurants. Before doing so, we first provide evidence that grade cards indeed cause a decrease in the number of people getting food-related sickness, and then consider the relevance of the competing mechanisms which potentially underly this outcome.

\section{Decrease in Food-Related Illnesses Due to Hygiene Grade Cards}

Table V presents summary statistics for digestive disorders contained in the OSHPD hospital admission data. In the table we distinguish Los Angeles county from the rest of California, and we distinguish food-related from non-food-related digestive disorders, based on the principal diagnosis. The principal diagnosis is defined according to the standard International Classification of Diseases (ICD-9-CM codes) and we use two sources for determining which codes correspond to illnesses that are likely to have been incurred via foodborne transmission. First, Mead et-al [2000] in their analysis of food-related illness provides a break-down we can apply as they do. Second, we obtained the help of an independent medical researcher who identified for us the codes that correspond to conditions that are food-related in over 90 percent of cases. ${ }^{48}$ There were no substantive differences in the content of the two sources. In Table V we measure food-related illnesses based on the definition by the medical researcher. ${ }^{49}$

Between 1995 and 1999 the number of hospital admissions for food-related illnesses in Los Angeles county varied between 309 and 431 per year, as shown in Table V. ${ }^{50}$ In Los Angeles the restaurant hygiene grade cards began to be implemented in January of 1998. In that year there was a 13.3 percent decrease in hospital admissions for food-related digestive disorders in Los Angeles, relative to the year before. Importantly, non-food-related admissions in Los Angeles increased by 2.9 percent over the same period of time. In addition, if one looks at food-related digestive disorders in the rest of California in 1998, there was a 3.2 percent increase in hospitalizations from the prior year. Moreover, the percent reduction in food-related admissions in Los Angeles in 1998 is the largest year-to-year percent change of any year, whether food-related or non-food-related, and whether within or outside of Los Angeles. This is basic and compelling

\footnotetext{
${ }^{47}$ The specific mechanism could matter in terms of designing the inspection regime. For example, if sorting is the only effect of grade cards, then less frequent inspections may suffice and be less costly.

${ }^{48}$ The medical researcher also identified the conditions that are food-related in over 50 percent of cases, which we use for robustness checks. The categorization of illnesses is available on request from us.

${ }^{49}$ The table changes very little if we define food-related illnesses based on the 50 percent criteria.

${ }^{50}$ Los Angeles county contains roughly 3.5 percent of the total United States population, suggesting there may be around 9,000 hospitalizations per year for food-related illnesses in the United States.
} 
evidence in favor of hygiene grade cards causing an improvement in actual health outcomes.

To more closely examine whether the grade cards cause a reduction in the number of hospital admissions for food-related illnesses we estimate the following specification

$$
\ln \left(a_{i j t}\right)=\alpha_{i j}+\tau_{t}+\beta_{1} m_{i t}+\beta_{2} v_{i t}+\gamma_{1} \text { food }_{i j t} m_{i t}+\gamma_{2} \text { food }_{i j t} v_{i t}+\epsilon_{i j t},
$$

where $a_{i j t}$ is the number of hospital admissions for digestive disorders in 3-digit-zip $i$, of type $j$ (either food-related or non-food-related), in month $t$. The variable $m \in[0,1]$ measures the share of the 3-digit-zip that is subject to mandatory disclosure of restaurant hygiene grade cards in that month. Similarly, $v \in[0,1]$ measures the share of the zip that is subject to voluntary disclosure in that month. The dummy variable food equals one for food-related digestive disorders and zero otherwise. We include fixed-effects for each 3-digit-zip and illness-type combination $\left(\alpha_{i j}\right)$ as well as year and month dummies $\left(\tau_{t}\right)$. To provide conservative estimates of the standard errors, which are robust to possible serial correlation, we also include random-effects for each 3-digit-zip and illness-type combination. Finally, $\epsilon$ is a residual and the terms $\beta$ and $\gamma$ are parameters to be estimated.

In equation (3) the $\beta$-coefficients capture the effects of the grade cards on admissions for nonfood-related digestive disorders. We expect these effects to be zero. Meanwhile the $\gamma$-coefficients capture the effects of the grade cards on admissions for food-related digestive disorders. If the grade cards cause a real improvement in restaurant hygiene, or if the grade cards facilitate consumer sorting toward restaurants with better hygiene, the $\gamma$-coefficients should be negative. The panel data we use for estimation cover all of California, before and after the grade cards are implemented in Los Angeles, and for food-related and non-food-related digestive disorders. ${ }^{51}$ Consequently, identification of the coefficients comes from three sources of variation: (i) in some regions we observe the level of admissions before and after the introduction of grade cards, (ii) we observe regions with and without grade cards at the same time, and (iii) we observe admissions for food-related digestive disorders as well as non-food-related digestive disorders in the same region at the same time. In other words, identification is based on time-series variation and cross-sectional variation provided by the presence of two control groups: California outside of Los Angeles and admissions for non-food-related digestive disorders.

Our data contain 57 3-digit-zips in California. In Los Angeles county there are about 18 3-digit-zips. ${ }^{52}$ There are multiple cities within each 3-digit-zip and, as discussed above, the adoption of mandatory posting of restaurant grade cards occurred at different times in different cities. ${ }^{53}$ These features of the data require us to compute the proportion of each 3-digit-zip

\footnotetext{
${ }^{51}$ We include only data for hospitalizations for digestive disorders.

${ }^{52} 3$-digit-zips overlap county boundaries. There are 12 3-digit-zips fully inside of Los Angeles county.

${ }^{53}$ Recall that voluntary posting of grade cards immediately applies in all cities in Los Angeles county following January 16, 1998.
} 
that is subject to mandatory and voluntary disclosure in each month ( $m$ and $v$ in the above specification). This is accomplished using census data to determine the share of the total 3digit-zip population subject to each policy regime. ${ }^{54}$

Table VI reports the estimates for the coefficients in equation (3), based on food-related illnesses defined as any principal diagnosis for which at least 90 percent of occurrences are transmitted by food. The estimate for the effect of mandatory grade cards on non-food-related admissions is insignificantly different from zero, as expected. The estimate for the effect of voluntary disclosure of grade cards on non-food-related admissions is significant, though positive. This is presumably a spurious correlation, since there is no reason to expect grade cards would cause an increase in non-food-related illnesses. It is also evidence against there being a downward trend in the incidence of digestive illnesses in general, in Los Angeles around this time. For food-related illnesses, we estimate the policy of mandatory posting of grade cards causes a highly statistically significant twenty percent decrease in hospitalizations. ${ }^{55}$ The policy of voluntary posting of grade cards is estimated to cause a 13 percent decrease in foodborne illness hospitalizations. ${ }^{56}$ Overall, these estimates reinforce the interpretation that there was not a coincidental reduction in digestive-disorders in Los Angeles county in 1998, that had nothing to do with the introduction of the restaurant grade cards. If this were so, we would expect to find negative coefficients on the non-food-related effects of mandatory and voluntary disclosure.

\section{Consumer Sorting and Improvements in Restaurants' Hygiene}

The above analysis of hospitalizations indicates the restaurant grade cards cause a decrease in the number of hospitalizations for foodborne illnesses. Moreover, this effect appears quite large in magnitude - perhaps as large as a twenty percent decrease in admissions. This suggests restaurants did make actual hygiene improvements, but it is not the only interpretation. Our revenue analysis indicates that prior to the grade cards, consumers are insensitive to changes in restaurant hygiene, presumably because they observe very little about it. With grade cards, however, consumers become quite sensitive to restaurant hygiene. Most likely there is a shift in demand away from poor hygiene restaurants toward good hygiene restaurants, which should contribute to the decrease in food-related hospitalizations. We call this the consumer-sorting effect on hospitalizations. In addition, grade cards may cause an improvement in supermarket hygiene, leading to fewer illnesses from eating at home, which may contribute to the decrease

\footnotetext{
${ }^{54} \mathrm{As}$ we also know the specific date of a policy change in each city, we also weight by the appropriate number of days to compute the population-and-days-weighted average values for $m$ and $v$ in each 3-digit-zip in each month. These are the variables used in estimation.

${ }^{55}$ The net effect is the sum of the coefficients on Mandatory Disclosure (.0271) and Food-Related times Mandatory Disclosure (-.2243).

${ }^{56}$ If we use the broader definition for food-related illness (ie. that at least 50 percent of occurrences are due to food) and re-estimate equation (3) the effects of both mandatory and voluntary disclosure on food-related hospitalizations are very similar.
} 
in food-related hospitalizations. ${ }^{57}$ Finally, the grade cards may encourage substitution from eating at home toward eating at restaurants, possibly also contributing to the reduction in hospitalizations. We now seek to separate these effects from the effect due to actual hygiene improvements by restaurants. In doing so, we answer the question: is at least part of the decrease in food-related hospitalizations caused by the grade cards due to restaurants making actual hygiene improvements?

We utilize our revenue data together with local population data to separate these effects. In each quarter and in each 3-digit-zip, we compute the aggregate revenue obtained by restaurants in various quantiles of the hygiene score distribution. By focusing on quantiles of the hygiene score distribution rather than absolute scores, we allow for the possibility that absolute scores may be arbitrary and subject to grade inflation. We then observe changes in revenue shares of the different quantiles of the hygiene distribution, allowing us to control for the consumer-sorting effect. To control for substitution from home eating to restaurant meals we use observed changes in total revenue (across all restaurants). And we use the interaction of population with grade cards to help control for the improved supermarket hygiene effect. To clarify the approach, we now present a formal framework.

Let $a_{i t}$ denote the number of hospital admissions for food-related illness in 3-digit-zip $i$ in quarter $t .{ }^{58}$ We assume $a$ is equal to the number of people living in the region, pop $i$, times the probability of an individual receiving a foodborne illness, either from eating at home or at restaurants. That is

$$
a_{i t}=\operatorname{pop}_{i}\left[x_{i t} p_{i t}^{r}+\left(1-x_{i t}\right) p_{i t}^{h}\right]
$$

where $x \in[0,1]$ is the fraction of meals consumed in restaurants and $(1-x)$ is the fraction consumed at home, $p^{r}$ is the probability of contracting a foodborne illness from a restaurant that results in a hospitalization, and similarly for $p^{h}$ from home. The term inside the square brackets of equation (4) is the probability of each person contracting a foodborne illness that results in hospitalization in that quarter.

We compute aggregate revenue for restaurants in each quantile of the hygiene score distribution. Specifically, we consider three segments of the hygiene score distribution, which we term the A-tile, B-tile and C-tile. The A-tile is defined as the segment of the score distribution corresponding to restaurants that have an A-grade (a current score of 90 or higher) at the end of 1998. More specifically, suppose that in region $i, Y_{i}$ percent of restaurants have a current score of 90 percent or higher at the end 1998, and hence an A-grade card. In every quarter, from 1996 to 1998 , the A-tile is defined as the top $Y_{i}$ percent of the score distribution. In periods other than the final quarter of 1998, restaurants in the A-tile need not have scores greater or equal to

\footnotetext{
${ }^{57}$ As noted above, the DHS also inspects supermarkets and issues them grade cards.

${ }^{58}$ While the admissions data is monthly, the revenue data is quarterly.
} 
90, and will generally include restaurants with scores below 90. By construction, the fraction of restaurants in the A-tile is the same over time in a given region, but differs across regions. The B-tile is similarly defined as the segment of the score distribution that possess a B-grade at the end of 1998 (a score in the 80s). The C-tile is the lower tail with scores below 80 at the end of 1998. This approach supposes that relative scores from DHS inspections are meaningfulrestaurants with higher inspection scores possess higher quality hygiene - allowing for absolute scores to be irrelevant. Importantly, this is not an assumption relied upon for estimation, as we do not require our estimates to imply that relatively higher scores be associated with fewer hospitalizations. ${ }^{59}$ The reason for using the A-tile, B-tile and C-tile approach, instead of other quantiles, is because the grade cards promote substitution across restaurants of different grades ( $\mathrm{A}, \mathrm{B}$ or $\mathrm{C}$ ) and not across restaurants with the same grade.

The probability of getting sick at a restaurant, $p^{r}$, can be broken down according to the revenue-share-weighted probabilities of getting sick at restaurants of different hygiene qualities:

$$
p_{i t}^{r}=s_{i t}^{a}\left(p^{a}+\theta^{r} g_{i t}\right)+s_{i t}^{b}\left(p^{b}+\theta^{r} g_{i t}\right)+s_{i t}^{c}\left(p^{c}+\theta^{r} g_{i t}\right),
$$

where $s^{a} \in[0,1]$ denotes the revenue share obtained by restaurants in the A-tile of the score distribution. Similarly for $s^{b}$ and $s^{c}$, with $s^{a}+s^{b}+s^{c}=1$. We denote $p^{a}$ as the probability (prior to the grade cards) of a meal at a restaurant in the A-tile leading to hospitalization, and similarly for $p^{b}$ and $p^{c}$. The variable $g$ is defined as a dummy equal to one if there are posted grade cards, and zero otherwise. Hence, $\theta \in[-1,0]$ represents actual hygiene improvements due to the grade cards that lower the probability of getting sick. ${ }^{60}$ This formulation distinguishes changes in $p^{r}$ that are due to actual hygiene improvements made by restaurants, from changes in $p^{r}$ that are due to changes in market shares, or consumer-sorting.

The grade cards may also cause improvements in hygiene quality at supermarkets, leading to safer home cooked meals. To allow for this possibility we let the probability of getting sick from eating at home also depend on the grade cards:

$$
p_{i t}^{h}=p^{h}+\theta^{h} g_{i t} .
$$

For the variable $x_{i t}$ in equation (4), the fraction of meals consumed in restaurants, we want a measure that is increasing in the total revenue of restaurants and decreasing in the total income or size of the market (all else equal). We use the proxy $x_{i t}=T R_{i t} / p o p_{i}$, where $T R$ is total restaurant revenue. This is actually an important component to the framework, since we show above that grade cards cause an increase in average restaurant revenue, which could be interpreted as substitution from eating at home to eating at restaurants. If eating at home

\footnotetext{
${ }^{59}$ Though our estimates do indeed reveal this to be the case.

${ }^{60}$ For simplicity, we assume the effects of the grade cards on these conditional probabilities are the same for each quantile, if there is any effect at all.
} 
has a higher probability of illness than eating in restaurants, then this effect is akin to the consumer-sorting effect and may also help explain the decrease in hospitalizations.

Substituting equation (5), equation (6) and the proxy for $x$ into equation (4), yields

$$
a_{i t}=\left(p^{a}-p^{h}\right) r_{i t}^{a}+\left(p^{b}-p^{h}\right) r_{i t}^{b}+\left(p^{c}-p^{h}\right) r_{i t}^{c}+\left(\theta^{r}-\theta^{h}\right) T R_{i t} g_{i t}+\theta^{h} p o p_{i} g_{i t} .
$$

The variable $r_{i t}^{a}$ is the actual revenue, not revenue share, of restaurants in the A-tile of the score distribution of 3-digit-zip $i$ in quarter $t$, similarly for $r_{i t}^{b}$ and $r_{i t}^{c}$. In equation (7) the following variables are data: $r_{i t}^{a}, r_{i t}^{b}, r_{i t}^{c}, T R_{i t}, g_{i t}$ and $p_{o} p_{i}$. The remaining variables are parameters to be estimated. The empirical counterpart of equation (7), the specification we actually estimate, is given by

$$
a_{i t}=\beta_{a} r_{i t}^{a}+\beta_{b} r_{i t}^{b}+\beta_{c} r_{i t}^{c}+\theta_{1} T R_{i t} g_{i t}+\theta_{2} p o p_{i} g_{i t}+\epsilon_{i t},
$$

where the $\beta$ and $\theta$ terms are estimated parameters and $\epsilon$ is a residual. ${ }^{61}$ Comparing equation (8) with equation (7) reveals that $\beta_{a}=p^{a}-p^{h}$. With this approach we are therefore unable to separately identify $p^{a}$ and $p^{h}$. Similarly, we are unable to separate $p^{b}$ and $p^{c}$ from $p^{h}$. However, we do identify each of $p^{a}, p^{b}$ and $p^{c}$ relative to $p^{h}$, in which case relative magnitudes of the estimated $\beta$ 's are of interest. Most importantly, though, we are able to separately identify $\theta^{r}$ and $\theta^{h}$ based on the estimates of $\theta_{1}$ and $\theta_{2}$. Specifically, $\theta^{r}=\theta_{1}+\theta_{2}$ and $\theta^{h}=\theta_{2}$. A finding that $\theta^{r}<0$ would be interpreted to imply that restaurants make actual hygiene improvements because of the grade cards. In estimating equation (8) we also control for seasonality in foodborne illness hospitalizations. Since the dependent variable is the number of admissions, the seasonal variation is likely to also depend on the population of each region. We therefore interact quarterly dummies with population in the estimated specification. Finally, we also include 3-digit-zip random-effects in order to obtain conservative estimates of the standard errors which are robust to the presence of possible serial correlation (as in the hygiene score and revenue regressions).

The coefficients in equation (8) are identified from cross-sectional and time-series variation in the market shares of restaurants in the A-tile, B-tile and C-tile of the hygiene score distribution and from time-series variation in the policy change. Consider a 3-period example. Suppose in the first period the aggregate revenues for each grade-tile are equal and the same across regions, and hospitalizations are equal across regions. In the second period, if there is a 3-digit-zip where the aggregate revenue obtained by the restaurants in the C-tile of the score distribution is higher, and if the number of hospitalizations is also higher in this region, all else equal, we will estimate $\beta_{c}>0$. Now suppose mandatory grade cards are introduced in the third period and the revenue of the C-tile restaurants in this region falls to the same as all other regions, and there are no other changes in revenues in this region or any other. If hospitalizations in

\footnotetext{
${ }^{61}$ For zips that overlap the boundary of Los Angeles county we weight the revenue variables by the proportion of the population in that zip living inside Los Angeles county.
} 
this region are now lower than any other region, then this implies actual hygiene improvements by supermarkets and/or restaurants. In this example, the decrease in hospitalizations following the introduction of grade cards is too large to be explained by the decrease in revenue for C-tile restaurants alone, implying that restaurants have made hygiene improvements.

While we have data on admissions for all of California, our revenue and inspection score data cover only Los Angeles county. An observation is a 3-digit-zip in a quarter in Los Angeles county from 1996 to 1998 and there are 191 such observations. Aggregation of the restaurantlevel data brings a couple of limitations for the analysis. First, it severely reduces the number of observations used in estimation. Second, we compound disaggregate shocks. For example, a family may eat chicken at home that was not correctly refrigerated in their house, leading to a number of hospitalizations. Both of these features hamper our ability to obtain precise estimates. This is also why we do not distinguish mandatory and voluntary disclosure of grade cards - to enhance our ability to obtain precise estimates of parameters of interest.

Table VII reports the estimated coefficients of the above specification. The point estimates for the $\beta$-coefficients (A-tile revenue, B-tile revenue and $\mathrm{C}$-tile revenue) indicate that meals at restaurants with relatively high scores are associated with fewer foodborne illnesses. ${ }^{62}$ The coefficient on A-tile revenue is less than the coefficient on B-tile revenue, which is also less than the coefficient on C-tile revenue. ${ }^{63}$ But only the coefficient on B-tile revenue is significantly different from zero. Hence, according to our estimates, eating at restaurants from the B-tile of the score distribution is more likely to lead to sickness than eating at home. The statistical insignificance of the coefficient on A-tile revenue does not imply the probability of getting sick from eating at restaurants in the A-tile of the hygiene score distribution is zero. Rather, that this probability is insignificantly different from the probability of getting sick from eating at home.

The estimate for the coefficient on A-tile revenue is the most precise of the estimated $\beta$ coefficients. This gives us confidence that the probability of getting sick from eating at home is the same as the probability of getting sick from eating at A-tile restaurants. ${ }^{64}$ The point estimate for the coefficient on C-tile revenue suggests that meals at these restaurants are the most likely to cause an illness, and with $95 \%$ confidence we are unable to reject the hypothesis that it is no different to eating at home. The higher standard error on the C-tile revenue effect is probably because we observe relatively few restaurants with a C-grade at the end of 1998, which has the consequence that C-tile revenue is more noisy than A-tile or B-tile revenue. Nevertheless,

\footnotetext{
${ }^{62}$ Literally, it is not "meals", but "dollars spent" that is in our approach. It does not matter in terms of the interpretation for our purposes.

${ }^{63}$ A larger coefficient means more hospitalizations.

${ }^{64}$ The 95 percent confidence interval for the coefficient on A-tile revenue is $[-.07, .04]$. This is narrow in comparison to the 95 percent confidence interval for the coefficient on B-tile revenue, which is [.17,.41].
} 
the ranking of the estimated $\beta$ 's is striking given the high degree of aggregation in the data, and suggests the DHS hygiene inspection scores are correlated with true restaurant hygiene. Furthermore, these results are encouraging of our framework.

We are primarily interested in the estimates for the $\theta$-parameters which concern whether restaurants make hygiene improvements because of the grade cards. The estimate for $\theta_{2}$, the coefficient on population times grade cards, is negative and significantly different from zero with 99 percent confidence. We interpret this to imply that meals at home are less likely to cause illness, due to the grade cards causing supermarkets to improve their hygiene quality. The estimate for $\theta_{1}$, the coefficient on total revenue times grade cards, is insignificantly different from zero. The estimate is fairly precise so the insignificance from zero is not primarily due to a large standard error - the 95 percent confidence interval for $\theta_{1}$ is $[-.01, .04] .{ }^{65}$ A finding of $\theta_{1}$ equal to zero implies the change in the probability of becoming sick from eating at particular restaurants, equals the change in the probability of becoming sick from eating at home. In other words, the estimates imply that restaurants, as well as supermarkets, make actual hygiene improvements in response to the grade cards.

Lastly, the estimates for the seasonality parameters reveal significant seasonality in the number of food-related illness hospitalizations. The third quarter appears to have the highest number of hospitalizations on average, while the first quarter has the lowest. The analysis in this section indicates the grade cards caused restaurants to make hygiene quality improvements, which contributed to the decrease in the number of foodborne illness hospitalizations. In the next subsection we present additional evidence to corroborate this finding.

\section{Other Evidence of Actual Hygiene Improvements}

We now examine the effect of grade cards on the incidence of particular hygiene violations. Inspectors do not directly assign scores, but instead record violations which imply a final score and our dataset includes information on the particular hygiene violations incurred in each inspection. If inspectors have modified their behavior due to the grade cards being implemented, then there must be a change in which violations are recorded. ${ }^{66}$ Some types of violations, such as improper employee hand-washing, are based on human behavior. Other types of violations are related to the physical structure of the restaurant, such as inadequate ventilation. Presumably it is harder for an inspector to ignore a violation of the latter kind than it is of the former. This could be because a subsequent inspection by a different inspector may raise a question if there is a physical structure violation that has obviously been present for some time. Hence, a finding

\footnotetext{
${ }^{65}$ In comparison, the 95 percent confidence interval for $\theta_{2}$ is [-5.80,-1.86].

${ }^{66}$ As noted earlier, prior to July 1997 there was an explicit subjective component of inspection scoring. Since July 1997, points are only deducted for noted violations that have pre-determined point-deductions associated with each.
} 
that there has been a decrease in the incidence of physical structure violations due to the grade cards may be more convincing evidence that restaurants have improved their hygiene quality, than simply showing that inspection scores have increased. ${ }^{67}$

We perform a regression in which the dependent variable is the number of points deducted for building structure violations. Specifically, the requirements of (i) lavatories in good repair, with hot and cold water available, adequate soap and towel dispenser, and a sufficient number of lavatories; (ii) adequate and approved ventilation in the cooking area and restrooms; (iii) clean walls and ceilings in good repair, easily cleanable and impervious to grease and moisture; and (iv) adequate lighting with shatterproof lights or light shields. The regressors are the same as equation (1) - dummies for mandatory disclosure, voluntary disclosure and the different inspection regimes, and restaurant fixed-effects. While not shown in a table, we find there are significant reductions in the average number of points deducted for building structure violations because of the introduction of both mandatory and voluntary grade cards. ${ }^{68}$

\section{Summary of Findings}

In this section we have examined evidence as to whether the introduction of grade cards cause a change in the scoring decisions of DHS inspectors without any change in true restaurant hygiene, or if restaurants actually do improve their hygiene quality. We show the presence of spikes in the distribution of inspection scores which strongly suggests inspectors behave differently when grade cards are involved. But we also find the grade cards cause a significant decrease in the number of people admitted to hospital with foodborne illnesses, and that this effect is not fully explained by consumers switching from bad to good hygiene restaurants. This implies that grade cards cause restaurants to make hygiene improvements. We also present some additional evidence concerning physical structure violations, which also support the case that grade cards cause restaurants to improve hygiene quality. Our conclusion is that the increased provision of product quality information to consumers causes firms to improve their product quality.

\footnotetext{
${ }^{67}$ There is second reason to be interested in the effect of grade cards on physical structure violations. Grade cards may have no lasting impact on restaurant hygiene if the only effect is to cause restaurant employees to be on better behavior when an inspector is present. If we observe significant decreases in the occurrence of violations related to the building structure as a result of the introduction of grade cards, then this would be evidence that the grade cards do not merely cause transient improvements in hygiene quality.

${ }^{68}$ The magnitude of the effect is equivalent to a 19 percent decrease in the number of building structure violations. All coefficients are significant at the 99 percent-level. This finding is further evidence of the grade cards causing restaurants to make actual hygiene improvements.
} 


\section{CONCLUSION}

This study examines the effects of a policy increasing the provision of information to consumers. We analyze a panel dataset for restaurants in Los Angeles county, covering before and after a sudden and unanticipated policy change in which restaurants are required to prominently display hygiene grade cards. The central finding is that hygiene grade cards cause restaurants to increase hygiene quality. To establish this, we show that (i) grade cards cause an increase in inspection scores, (ii) grade cards cause consumers to become sensitive to restaurant hygiene, and (iii) grade cards cause a decrease in the incidence of foodborne illness hospitalizations which is not fully explained by consumer-sorting.

The finding that grade cards reduce illnesses is fairly striking in itself. Providing people with better information causes people to change their purchase decisions and causes firms to modify their behavior, leading to improved health for people. Moreover, the effect is large in magnitude - possibly a twenty percent decrease in food-related hospitalizations. This result alone should encourage the introduction of restaurant hygiene grade cards in other regions. Though it would be ideal to conduct a more complete welfare analysis of the policy change, which would also examine consumer and producer surplus, this is beyond the scope of our study. The spiking in the hygiene score distribution with grade cards supports the concern that grade cards induce grade inflation for one reason or another. It is conceivable that changes in inspector behavior might undermine the usefulness of the grade cards in the longer term. This issue warrants further research.

Since disclosure of grade cards was initially voluntary for some restaurants, while mandatory for others, the policy change also provides an opportunity to examine whether voluntary disclosure can have the same effects as mandatory disclosure. As we have noted, there are a couple of reasons why this experiment in our dataset is not ideal. With these caveats in mind, our analysis indicates there are statistically significant differences between mandatory and voluntary disclosure, but the differences are small in magnitude. These findings, while not conclusive, may encourage policy-makers or private institutions to facilitate voluntary disclosure of verifiable product information in consumer-product markets.

One may wonder why restaurants did not disclose the results of their hygiene inspections prior to the grade cards. Why would a restaurant manager not create their own poster clearly showing their latest hygiene score, say, and display it in the window? ${ }^{69}$ Perhaps this indicates it is unprofitable for restaurants to increase the provision of hygiene quality information to

\footnotetext{
${ }^{69}$ We presume restaurants would be honest about their score since customers may ask to see the formal inspection results.
} 
consumers. An alternative interpretation is that such information does enhance profitability but it is important there exists a standard-format available for all restaurants to display. We find evidence of voluntary disclosure with the standard-format in support of this explanation. It seems remarkable that simply providing a standard-format for disclosure, with no change in inspections or closure criteria, would be sufficient to change the equilibrium from zero disclosure and low hygiene quality, to high hygiene quality with potentially full disclosure. ${ }^{70}$

Department of Economics, University of Maryland

Graduate School of Business, Stanford University

\section{REFERENCES}

Akerlof, George A., "The Market for 'Lemons': Quality Uncertainty and the Market Mechanism," Quarterly Journal of Economics, LXXXIV (1970), 488-500.

Benham, Lee, "The Effect of Advertising on Prices of Eyeglasses," Journal of Law and Economics, XV (1972), 337-52.

Butters, Gerard R., "Equilibrium Distributions of Sales and Advertising Prices," Review of Economic Studies, XLIV (1977), 465-91.

Chipty, Tasneem and Ann Dryden Witte, "Effects of Information Provision in a Vertically Differentiated Market," NBER Working Paper, \#6493 (1998).

Devine, D. Grant and Bruce W. Marion, "The Influence of Consumer Price Information on Retail Pricing and Consumer Behavior," American Journal of Agricultural Economics, LXI (1979), 228-37.

Dranove, David, Daniel Kessler, Mark McClellan and Mark Satterthwaite, "Is More Information Better? The Effects of 'Report Cards' on Health Care Providers," forthcoming Journal of Political Economy, (2000).

Easterbrook, Frank H. and Daniel R. Fischel, "Mandatory Disclosure and the Protection of Investors," Virginia Law Review, LXX (1984), 669-715.

\footnotetext{
${ }^{70}$ See Easterbrook and Fischel [1984] for a discussion of these issues. A remaining question is why a private third party did not create a standard-format for all restaurants before grade cards were introduced. A leading example is restaurant guide books, such as Zagats. They may not publish restaurant hygiene ratings because restaurants are inspected by the DHS more frequently than the guide book is published.
} 
Farrell, Joseph, "Voluntary Disclosure: Robustness of the Unraveling Results and Comments on Its Importance," in R. Greison (ed.) Antitrust and Regulation, (Lexington Books, 1986).

Fishman, Michael J. and Kathleen M. Hagerty, "Mandatory Disclosure," in P. Newman (ed.), The New Palgrave Dictionary of Economics and the Law, (London, Macmillan Press, 1998).

Fishman, Michael J. and Kathleen M. Hagerty, "Mandatory vs. Voluntary Disclosure in Markets with Informed and Uninformed Customers," Mimeo, (Northwestern University, 1999).

Grossman, Sanford J., "The Informational Role of Warranties and Private Disclosure about Product Quality," Journal of Law and Economics, XXIV (1981), 461-489.

Jin, Ginger Zhe, "Competition and Disclosure Incentives: An Empirical Study of HMOs," Mimeo, (University of Maryland, 2000a).

Jin, Ginger Zhe, "Detecting the Impact of Competition on Disclosure Incentives," Mimeo, (University of Maryland, 2000b).

Jovanovic, Boyan, "Truthful Disclosure of Information," Bell Journal of Economics, XIII (1982), 36-44.

Kézdi, Gábor, "Robust Standard Error Estimation In Fixed-Effects Panel Models," Mimeo, (University of Michigan, 2002).

Kwoka, John E., "Advertising and the Price and Quality of Optometric Services," American Economic Review, LXXIV (1984), 211-16.

Mathios, Alan D., "The Impact of Mandatory Disclosure Laws on Product Choices: An Analysis of the Salad Dressing Market," Journal of Law and Economics, XLIII (2000), 651-78.

Mead, Paul S., Laurence Slutsker, Vance Dietz, Linda F. McCraig, Joseph S. Bresee, Craig Shapiro, Patricia M. Griffin and Robert V. Tauxe, "Food-Related Illness and Death in the United States," Journal of Environmental Health, LXII (2000), 9-18.

Milgrom, Paul, "Good News and Bad News: Representation Theorems and Applications," Bell Journal of Economics, XII (1981), 380-91.

Milgrom, Paul and John Roberts, "Price and Advertising Signals of Product Quality," Journal of Political Economy, XCIV (1986), 796-821.

Milyo, Jeffrey and Joel Waldfogel, "The Effect of Price Advertising on Prices: Evidence in the Wake of 44 Liquormart," American Economic Review, LXXXIX (1999), 1081-1096.

Nelson, Phillip, "Information and Consumer Behavior," Journal of Political Economy, LXXVIII (1970), 311-329.

Salop, Steven and Joseph Stiglitz, "Bargains and Ripoffs: A Model of Monopolistically Competitive Price Dispersion," Review of Economic Studies, XLIV (1977), 493-510. 
Stigler, George J., "The Economics of Information," Journal of Political Economy, LXIX (1961), 213-25.

Teisl, Mario F. and Brian Roe, "The Economics of Labeling: An Overview of Issues for Health and Environmental Disclosure," Agricultural and Resource Economics Review, XXVII (1998), 140-50. 


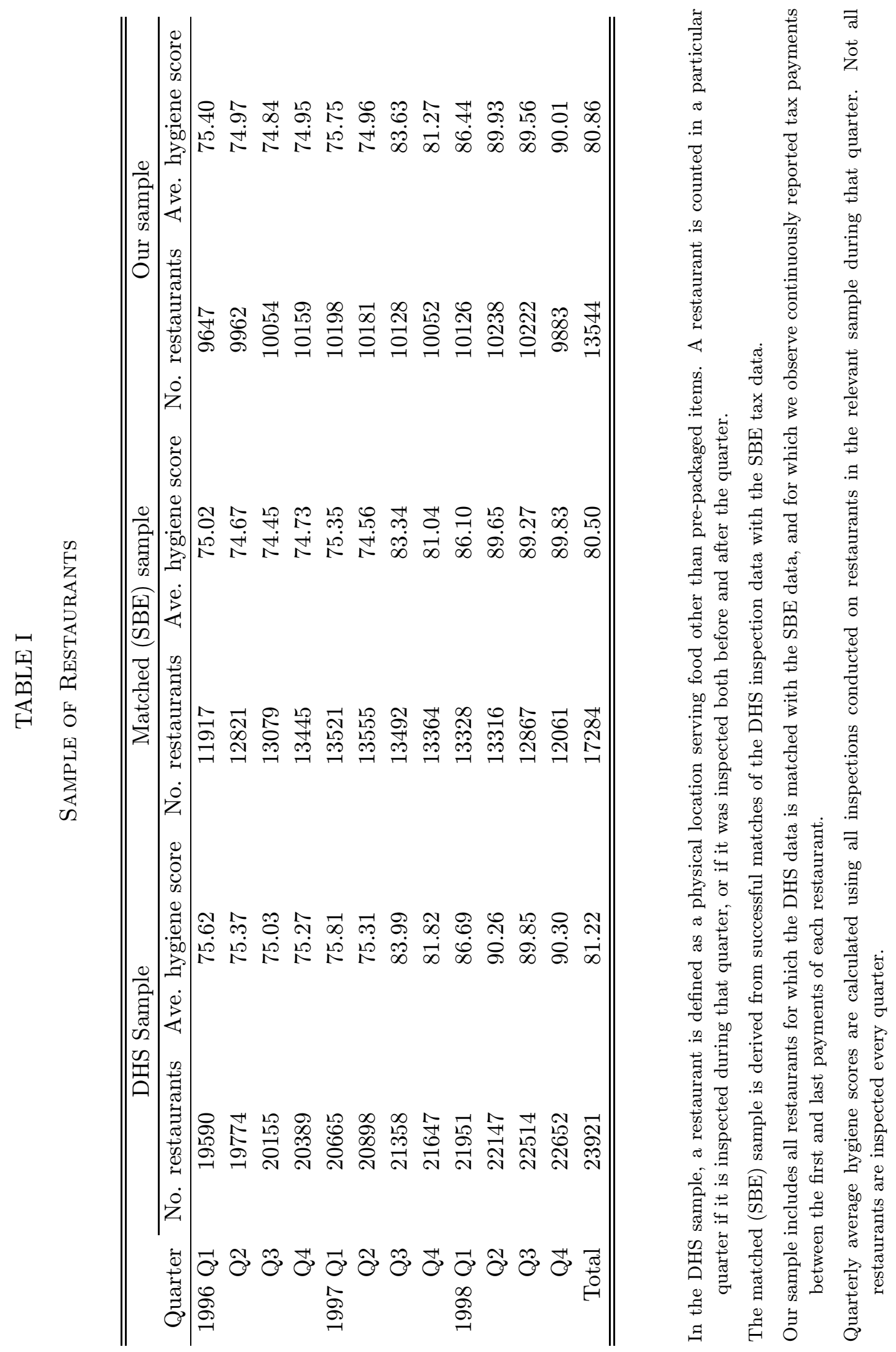




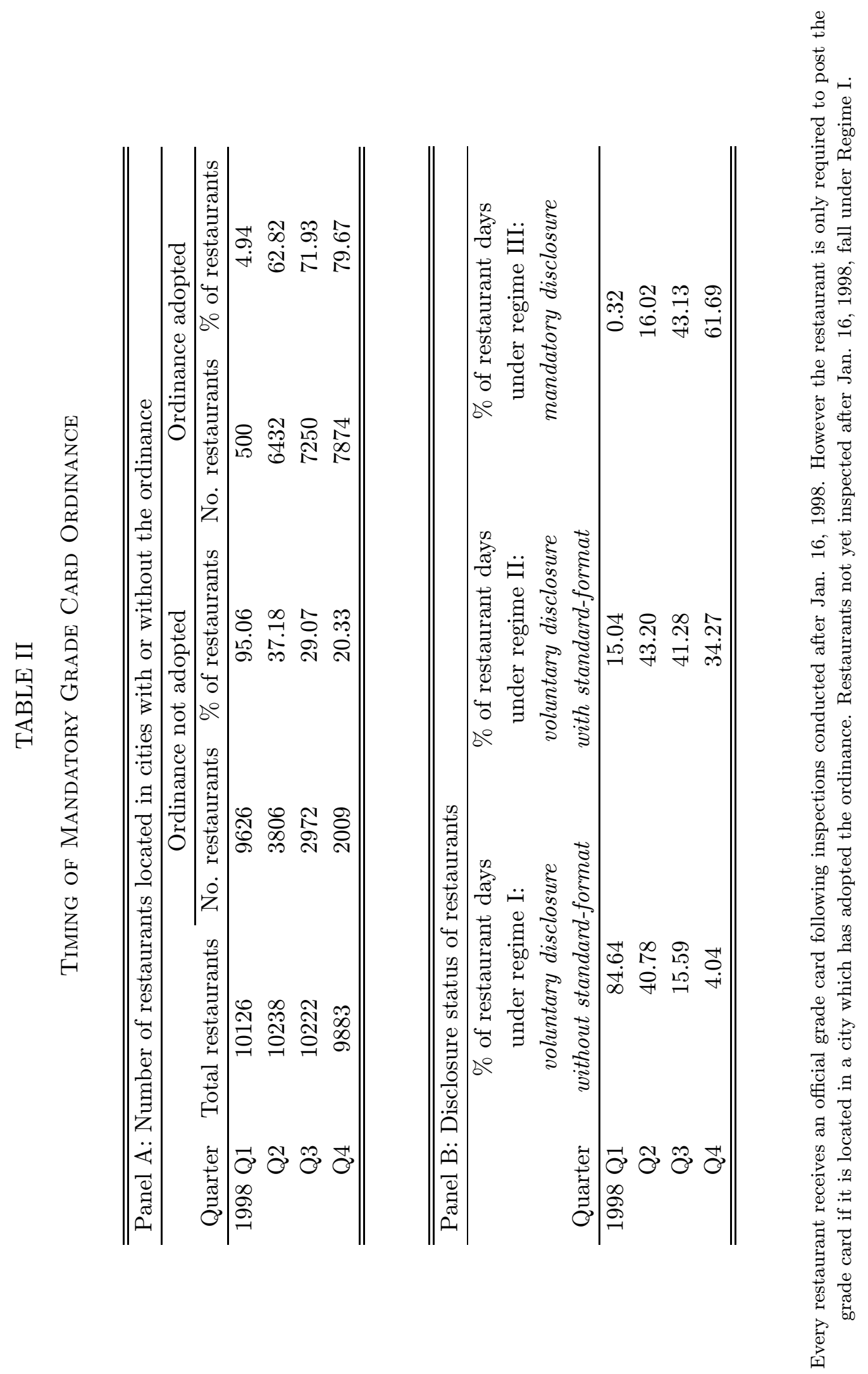


TABLE III

The Effects of Grade Cards and Disclosure Regulation on Hygiene Scores

\begin{tabular}{rccccc}
\hline \hline & \multicolumn{2}{c}{ Without fixed-effects } & & \multicolumn{2}{c}{ With fixed-effects } \\
\cline { 2 - 3 } \cline { 5 - 6 } & Coefficient & Std. error & & Coefficient & Std. error \\
\hline Mandatory disclosure & 4.9432 & $1.1384^{* * *}$ & & 4.3958 & $1.4046^{* * *}$ \\
Voluntary disclosure & 4.0585 & $0.3199^{* * *}$ & & 3.2528 & $0.3550^{* * *}$ \\
Inspection criteria II & 7.7192 & $0.9181^{* * *}$ & & 8.0886 & $0.9907^{* * *}$ \\
Inspection criteria III & 9.9838 & $1.2233^{* * *}$ & & 10.4158 & $1.3542^{* * *}$ \\
Observations & 69,991 & & & \\
No. restaurants & 13,544 & & & & \\
$R^{2}$ & 0.3574 & & 0.5874 & \\
\hline \hline
\end{tabular}

Regressions include city random-effects (ie. we cluster the standard errors by city with Huber-White standard errors).

In the regression without fixed-effects, while not reported, we also include the following restaurant characteristics: food type, food style, seating capacity, liquor license dummy, DHS risk assessment, and city dummies. Stars denote significance levels: 99 percent confidence level $(* * *), 95$ percent confidence level (**) and 90 percent confidence level $(*)$.

The voluntary disclosure dummy is for voluntary verifiable disclosure (ie. grade cards are issued but posting is discretionary). The excluded dummy is for voluntary non-verifiable disclosure (ie. prior to the introduction of grade cards).

Inspection Criteria II Dummy is for inspections carried out between 7/1/1997 and 3/18/1998. See text for further details.

Inspection Criteria III Dummy is for inspections carried after 3/18/1998. See text for further details. 


\section{TABLE IV}

\section{Effects of Grade Cards and Disclosure Regulation \\ on $\ln$ (Quarterly Restaurant Revenue)}

\begin{tabular}{rcl}
\hline \hline & Coefficient & Std. error \\
\hline Mandatory disclosure & 0.0569 & $0.0153^{* * *}$ \\
Voluntary disclosure & 0.0326 & $0.0149^{* *}$ \\
B-grade & -0.0074 & 0.0084 \\
C-grade & 0.0039 & 0.0074 \\
D-grade & -0.0023 & 0.0057 \\
Mandatory $\times$ B-grade & -0.0497 & $0.0151^{* * *}$ \\
Mandatory $\times$ C-grade & -0.0670 & $0.0304^{* *}$ \\
Mandatory $\times$ D-grade & -0.0565 & 0.0437 \\
Voluntary $\times$ B-grade & -0.0029 & 0.0128 \\
Voluntary $\times$ C-grade & -0.0238 & 0.0216 \\
Voluntary $\times$ D-grade & -0.0758 & 0.0469 \\
Missing grade & -0.0001 & 0.0096 \\
Observations & 74,321 & \\
$R^{2}$ & 0.9506 & \\
\hline \hline
\end{tabular}

The regression also includes a restaurant fixed-effects, a full set of quarterly dummies and city-level randomeffects (ie. we cluster the standard errors by city with Huber-White standard errors).

D-Grade is equivalent to any score below 70 (ie. less than a C-grade). Missing Grade is for restaurants that have opened but not yet been inspected.

Excluded dummy is for voluntary disclosure without a standard-format. Interactions with A grade are also excluded.

The sample size is slightly reduced because we discard (i) observations for the first and last quarter when a restaurant is a new entrant or exitor, since we do not know the date of entry or exit; (ii) observations with negative tax, and hence negative revenue (due to overpayment of tax in a prior quarter); and (iii) restaurants with merged tax accounts (see text for a detailed explanation).

Stars denote significance levels: 99 percent confidence level $(* * *), 95$ percent confidence level $(* *)$ and 90 percent confidence level $(*)$. 

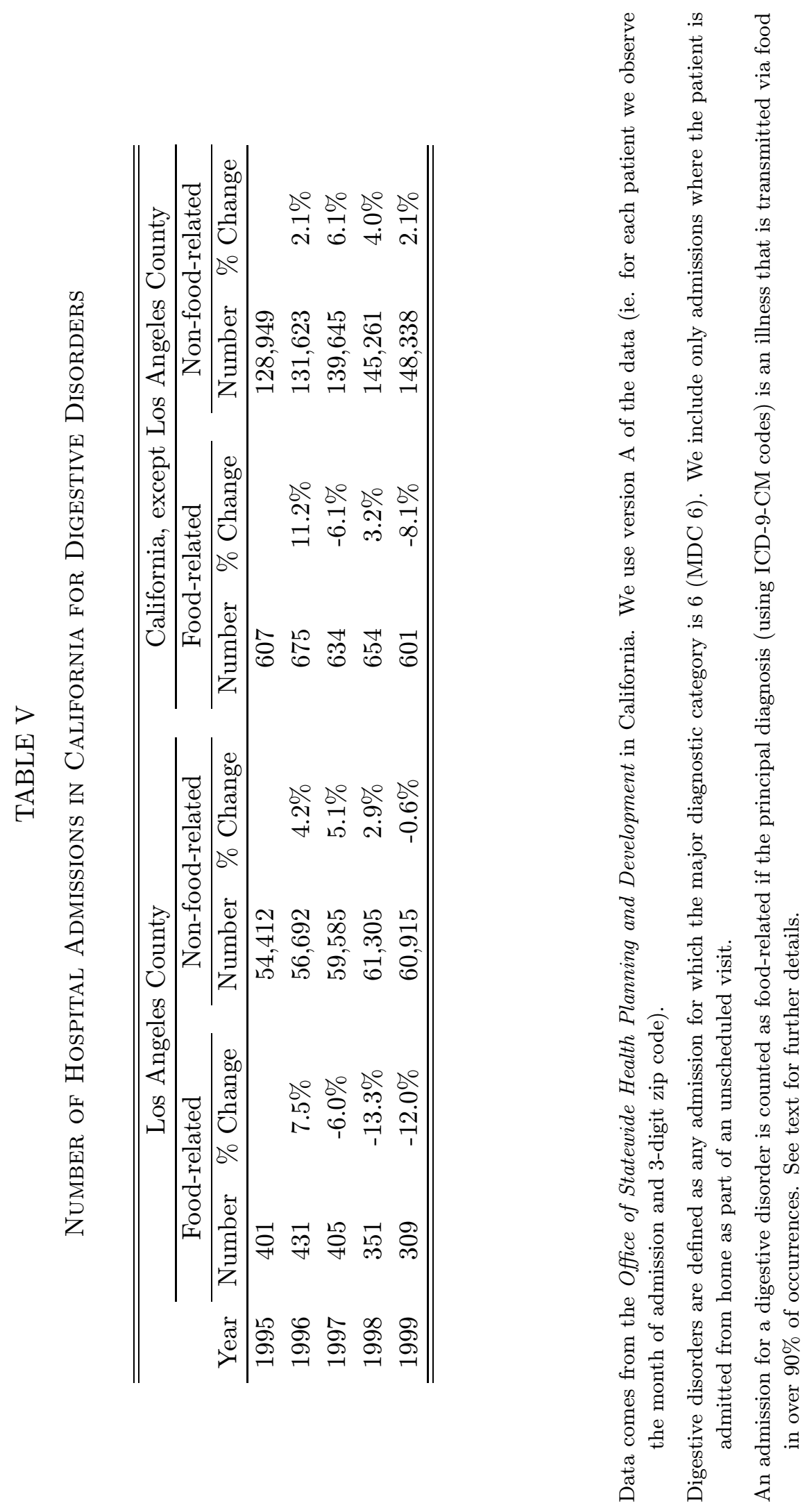


\section{TABLE VI}

The Effects of Grade Cards on

$\ln$ (No. Hospitalizations for Digestive Disorders)

\begin{tabular}{rcl}
\hline \hline & Coefficient & Std. Error \\
\hline Mandatory disclosure & 0.0271 & 0.0246 \\
Voluntary disclosure & 0.0716 & $0.0238^{* * *}$ \\
Food-related $\times$ mandatory disclosure & -0.2243 & $0.0426^{* * *}$ \\
Food-related $\times$ voluntary disclosure & -0.2055 & $0.0350^{* * *}$ \\
Observations & 6,840 & \\
$R^{2}$ & 0.9809 & \\
\hline \hline
\end{tabular}

Covariates not shown include fixed-effects for food-related illnesses in each 3-digit zip code, fixed-effects for non-food-related illnesses in each 3-digit-zip code, and year and month dummies. We also include 3digit-zip illness-type random-effects (ie. we cluster the standard errors by 3-digit-zip and illness-type with Huber-White standard errors).

Stars denote significance levels: 99 percent confidence level $(* * *), 95$ percent confidence level $(* *)$ and 90 percent confidence level $(*)$. 
TABLE VII

The Effects of Grade Cards on the Number of Food-Related Illness Hospitalizations

\begin{tabular}{rcl}
\hline \hline & Coefficient & Std. error \\
\hline A-tile revenue & -0.0146 & 0.0264 \\
B-tile revenue & 0.2892 & $0.0615^{* * *}$ \\
C-tile revenue & 1.1288 & $0.4367^{* *}$ \\
Total revenue $\times$ grade cards & 0.0156 & 0.0140 \\
Population $\times$ grade cards & -3.8327 & $1.0045^{* * *}$ \\
Q1 $\times$ population & 5.9537 & $1.0871^{* * *}$ \\
Q2 $\times$ population & 9.1979 & $0.7719^{* * *}$ \\
Q3 $\times$ population & 11.2465 & $1.3932^{* * *}$ \\
Q4 $\times$ population & 8.4846 & $1.1998^{* * *}$ \\
Observations & 191 & \\
$R^{2}$ & 0.9156 & \\
\hline \hline
\end{tabular}

The regression also includes 3-digit-zip random-effects (ie. we cluster the standard errors by 3-digit-zip with Huber-White standard errors).

Revenue variables are in units of $10^{6}$. Also, revenue is deflated using the BLS consumer price index for all urban consumers.

See text for a complete description of all variables.

Stars denote significance levels: 99 percent confidence level $(* * *), 95$ percent confidence level $(* *)$ and 90 percent confidence level $(*)$. 


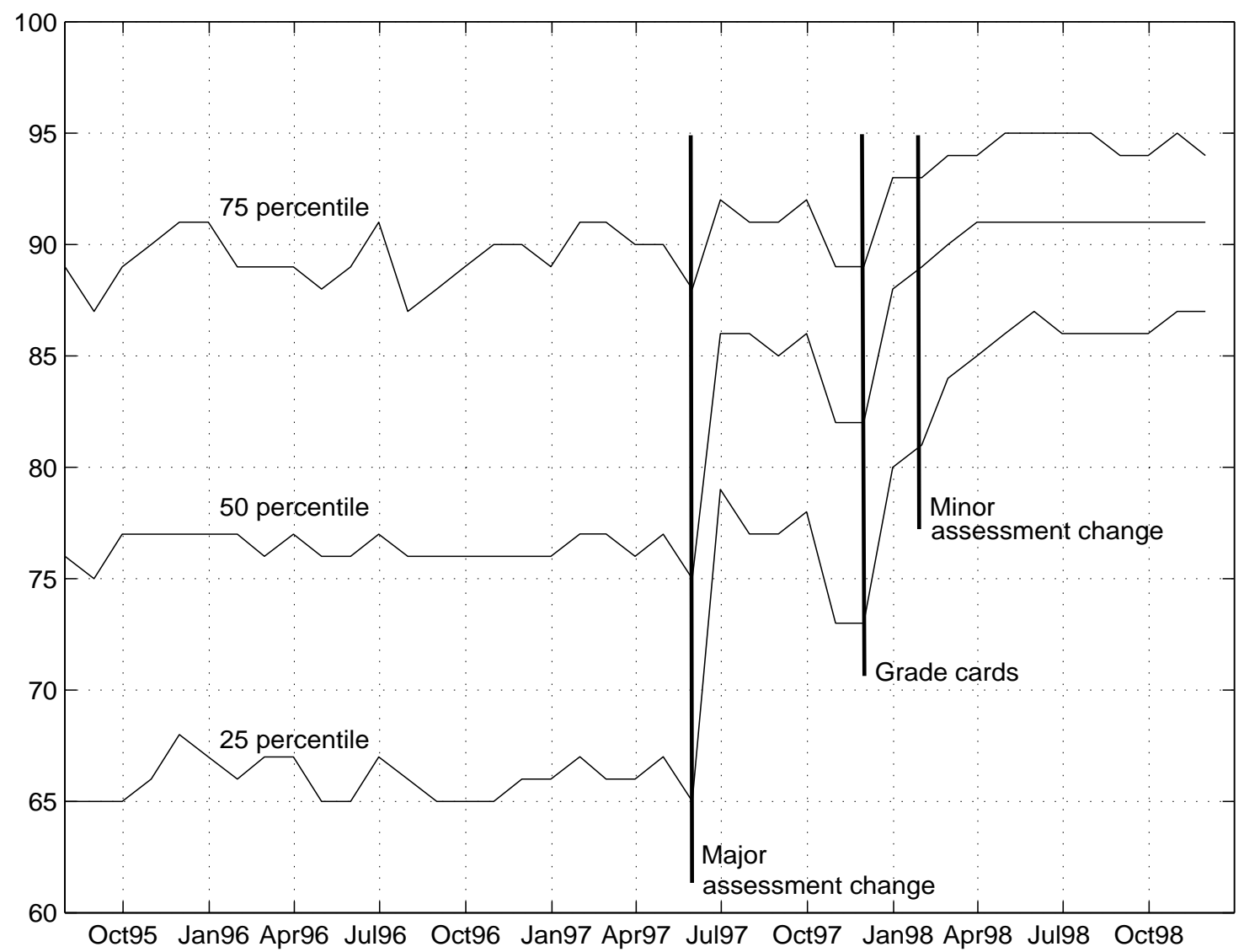

FIGURE I

Quartiles of Hygiene Quality Distribution over Time

Notes:

Quartiles are computed based on all inspections in a given month.

The assessment changes took place on $7 / 1 / 1997$ and 3/18/1998.

The grade cards began introduction on $1 / 16 / 1998$.

Vertical lines for regime changes are located immediately prior to a change in order to emphasize subsequent impacts on the hygiene distribution. 


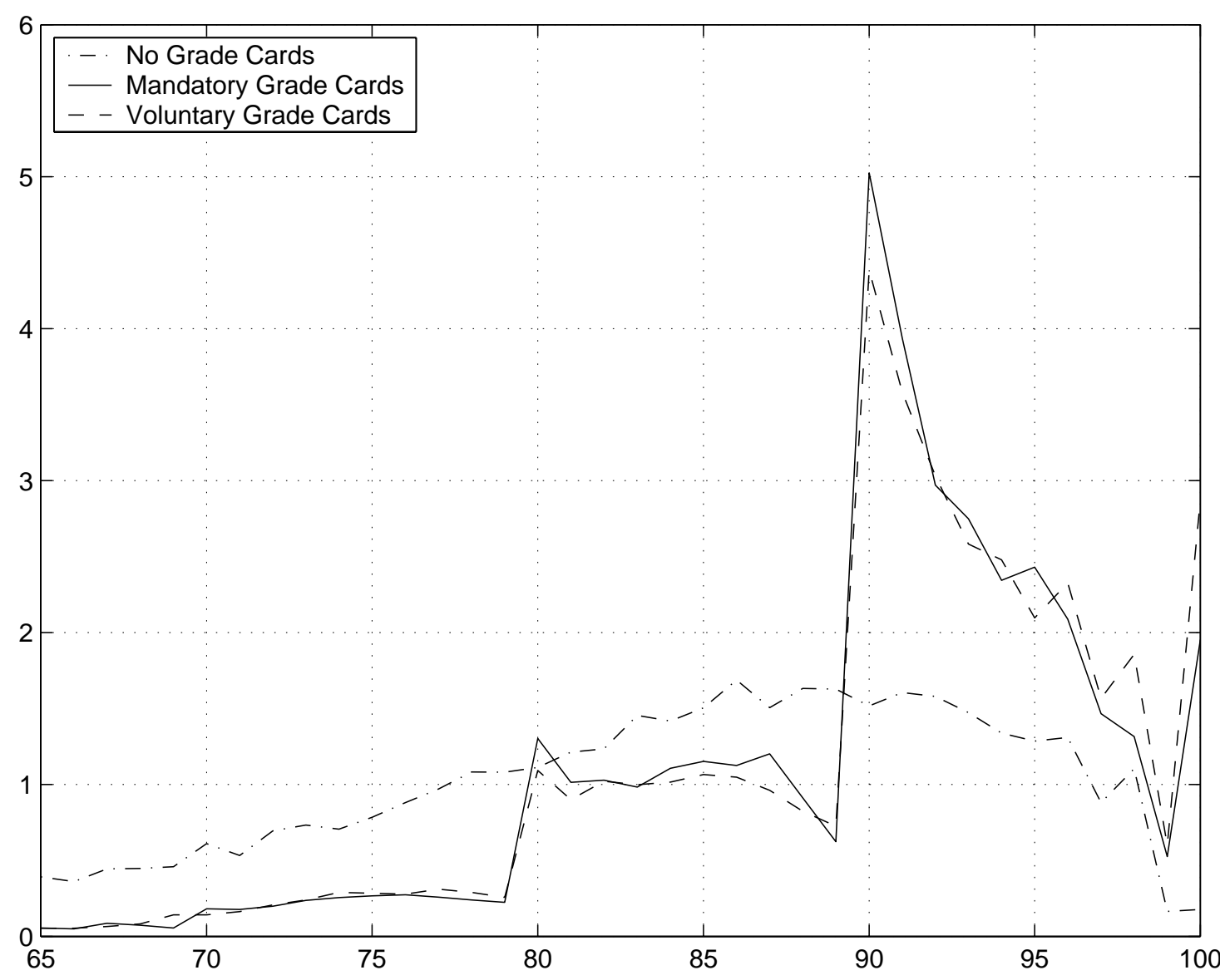

FIGURE II

\section{Distributions of Hygiene Scores Under Different Disclosure Regimes}

Notes:

The figure is no different to a histogram (or an unsmoothed non-parametric density).

Units on the vertical axis are meaningless. 